\title{
Drug-Induced Long QT Syndrome
}

\author{
Prince Kannankeril, Dan M. Roden, and Dawood Darbar
}

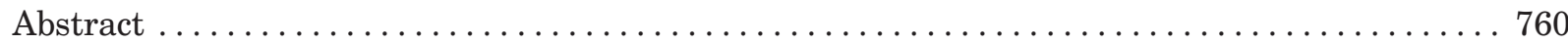

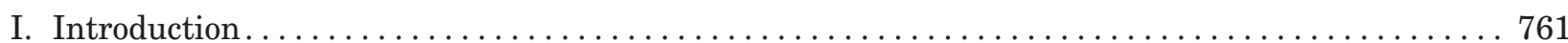

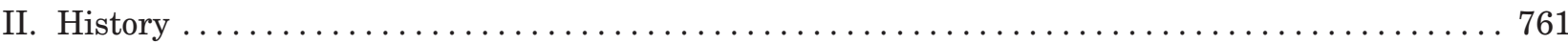

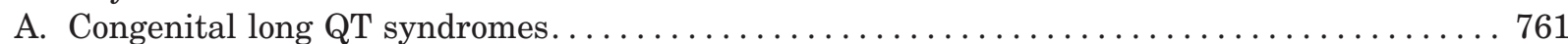

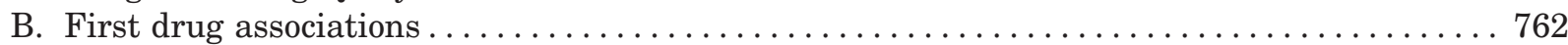

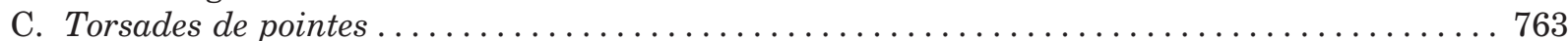

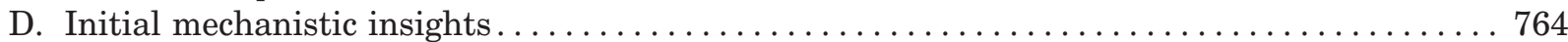

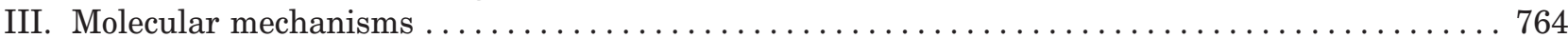

A. Congenital long QT syndrome informing the more common drug-induced long QT

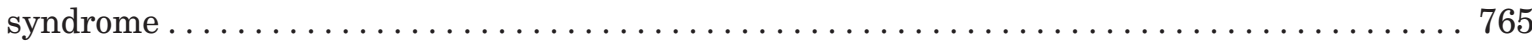

B. Mechanisms of QT prolongation in the drug-induced long QT syndrome........... 765

C. Mechanisms of proarrhythmia in the setting of QT prolongation $\ldots \ldots \ldots \ldots \ldots \ldots \ldots \ldots 766$

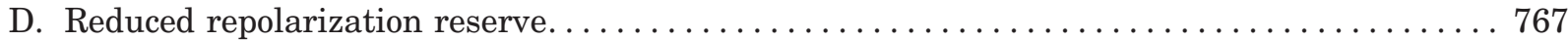

IV. Models of drug-induced long QT syndrome $\ldots \ldots \ldots \ldots \ldots \ldots \ldots \ldots \ldots \ldots \ldots \ldots \ldots \ldots \ldots$

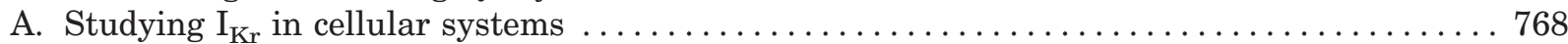

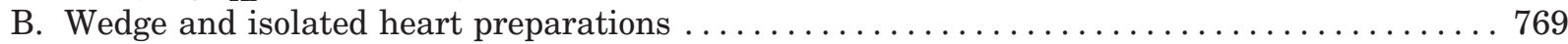

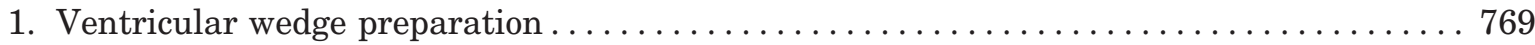

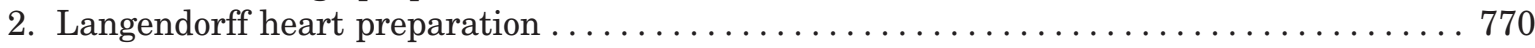

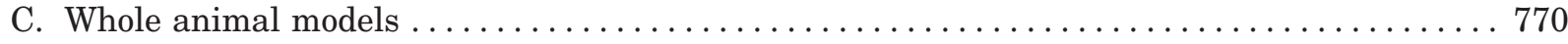

1. The methoxamine-sensitized rabbit model $\ldots \ldots \ldots \ldots \ldots \ldots \ldots \ldots \ldots \ldots \ldots \ldots \ldots \ldots \ldots$

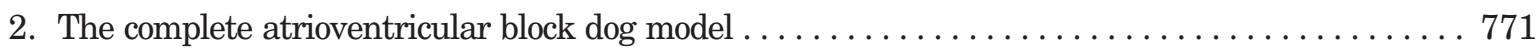

D. Triangulation, reverse use-dependence, instability, dispersion $\ldots \ldots \ldots \ldots \ldots \ldots \ldots \ldots 77$

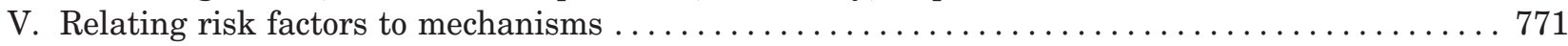

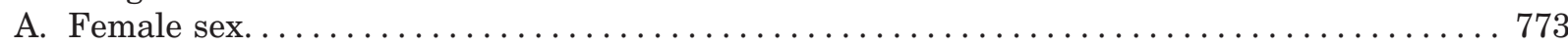

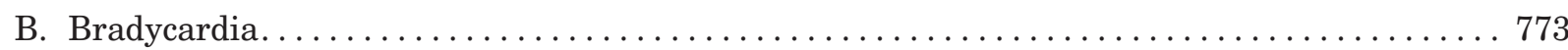

1. The "short-long-short" series of cycling changes before the initiation of an event ..... 773

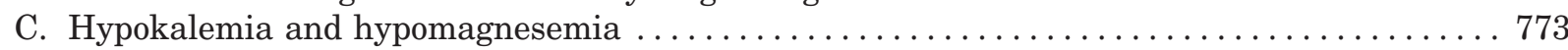

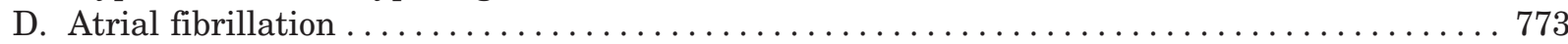

E. Role of variable drug concentrations in torsades de pointes risk . . . . . . . . . . . 774

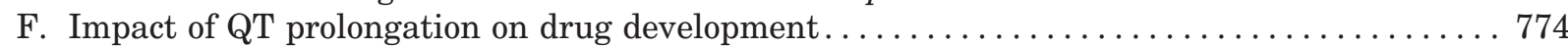

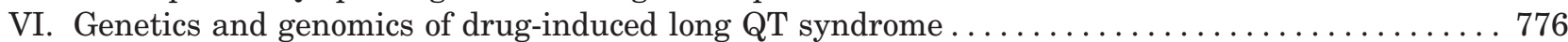

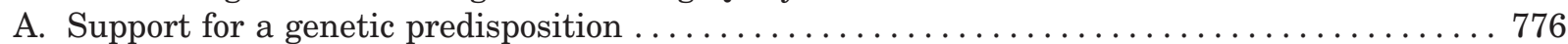

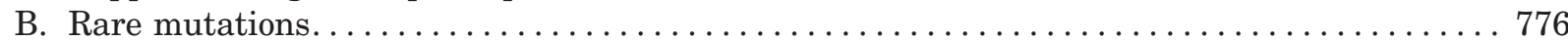

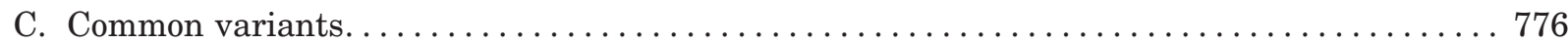

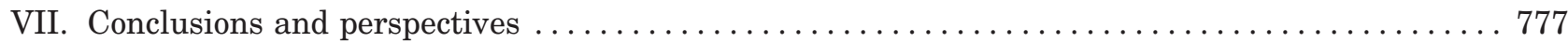

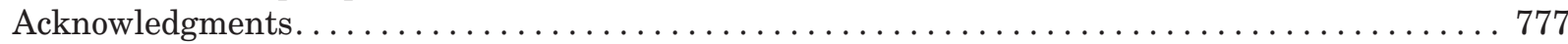

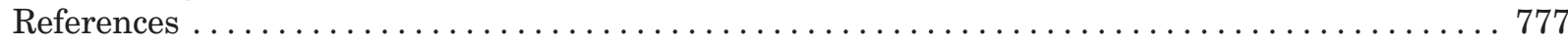

\footnotetext{
Abstract-The drug-induced long QT syndrome is a distinct clinical entity that has evolved from an

Address correspondence to: Dr. Dan M. Roden, Oates Institute for Experimental Therapeutics, Vanderbilt University School of Medicine, 1285 Medical Research Building IV, Nashville, TN 37232-0575. E-mail: dan.roden@vanderbilt.edu

This article is available online at http://pharmrev.aspetjournals.org. doi:10.1124/pr.110.003723.
}

electrophysiologic curiosity to a centerpiece in drug regulation and development. This evolution reflects an increasing recognition that a rare adverse drug effect can profoundly upset the balance between benefit and risk that goes into the prescription of a drug by an individual practitioner as well as the approval of a new drug entity by a regulatory agency. This review will outline how defining the central mechanism, block of the cardiac delayed- 
rectifier potassium current $I_{K r}$, has contributed to defining risk in patients and in populations. Models for studying risk, and understanding the way in which clinical risk factors modulate cardiac repolar- ization at the molecular level are discussed. Finally, the role of genetic variants in modulating risk is described.

\section{Introduction}

The drug-induced long QT syndrome (diLQTS $\left.{ }^{1}\right)$ describes a clinical entity in which administration of a drug produces marked prolongation of the QT interval of the electrocardiogram, associated with the development of a morphologically distinctive polymorphic ventricular tachycardia, termed torsades de pointes (TdP). Typical cases are shown in Figs. 1 to 3 and illustrate clinical features discussed further in section V: sex dependence; self-limited episodes of TdP; diLQTS developing after conversion of atrial fibrillation (AF) to normal rhythm; elevated drug concentrations as a result of impaired excretion; a stereotypical series of cycle length changes before the arrhythmia; and not only prolongation but also deformity of the QT interval, manifested as prominent " $U$ waves." Although the arrhythmia is frequently self-limited, degeneration to ventricular fibrillation and death can occur. The relationship between QT prolongation and risk for TdP is not straightforward, as discussed

\footnotetext{
${ }^{1}$ Abbreviations: AF, atrial fibrillation; APD, action potential duration; AV, atrioventricular; BVR, beat-to-beat variability of repolarization; CAVB, complete atrioventricular block; cLQTS, congenital syndromes of QT prolongation; diLQTS, drug-induced long QT syndrome; EAD, early afterdepolarization; ECG, electrocardiogram; LQTS, long QT syndrome; M cell, cell in the midmyocardium; SCD, sudden cardiac death; TdP, torsades de pointes; TDR, transmural dispersion of repolarization.
}

further below (section II.C). Accumulation of large series of cases of drug-induced TdP has allowed these and other clinical risk factors to be described, permitting identification of patients at especially high or especially low risk. Furthermore, identification of these clinical features has been a vital starting point in studies of underlying mechanisms.

\section{History}

The 1950s and 1960s saw the initial clinical descriptions of the congenital long QT syndromes, of druginduced arrhythmias, and of the distinctive arrhythmia TdP. By the end of the 1960s, the potential link among these entities was beginning to be recognized, and initial hypotheses about underlying mechanisms were formulated. This section outlines these initial findings, which set the stage for our current understanding of how ion channel dysfunction arising from diverse perturbations from electrolyte abnormalities to variants in ion channel genes modifies risk.

\section{A. Congenital Long QT Syndromes}

The uncommon congenital syndromes of QT prolongation (cLQTS) associated with a high risk of sudden death were first described in the 1950s and 1960s (Jervell and Lange-Nielsen, 1957; Romano et al., 1963; Ward, 1964).

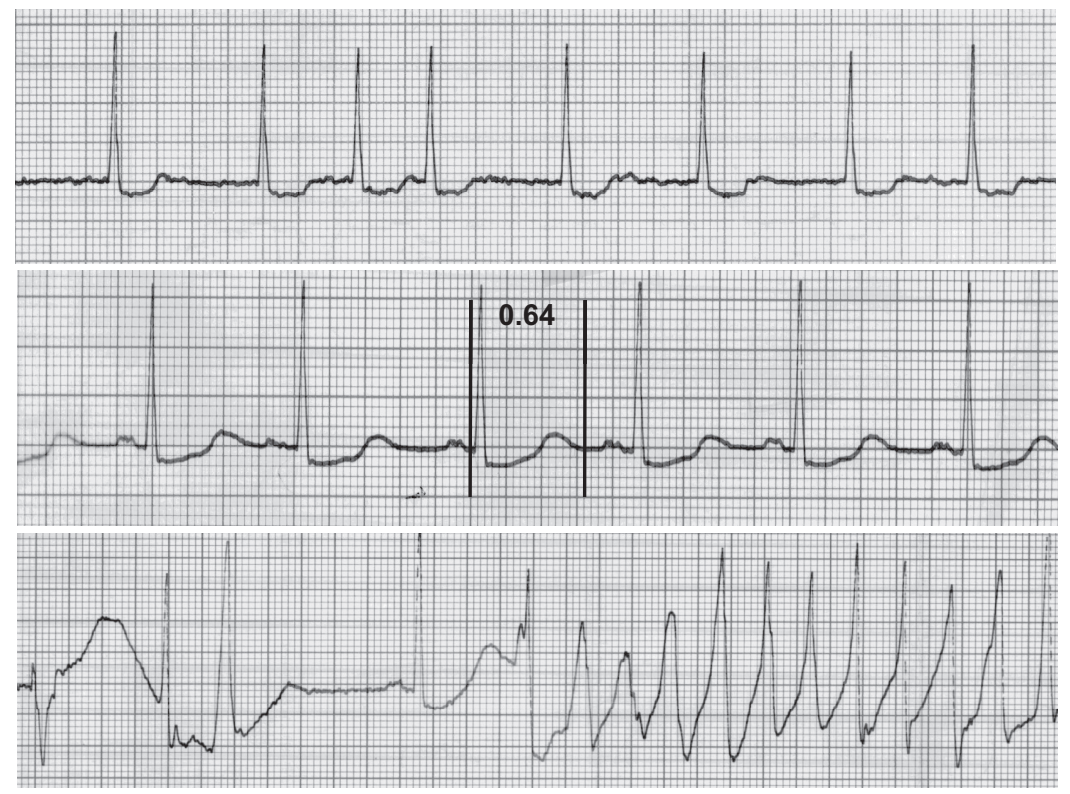

FIG. 1. Continuous recording from a patient who had recently begun receiving sotalol. During AF, there is irregularity of ventricular response, creating frequent short-long-short cycles but there is minimal change in QT intervals (top). After electrical cardioversion, the QT interval increased dramatically to $0.64 \mathrm{~s}$ (middle), and an episode of torsades de pointes is triggered (bottom). [Reprinted from Darbar D, Kimbrough J, Jawaid A, McCray R, Ritchie MD, and Roden DM (2008) Persistent atrial fibrillation is associated with reduced risk of torsades de pointes in patients with drug-induced long QT syndrome. J Am Coll Cardiol 51:836-842. Copyright @ 2008 Elsevier, Inc. Used with permission.] 


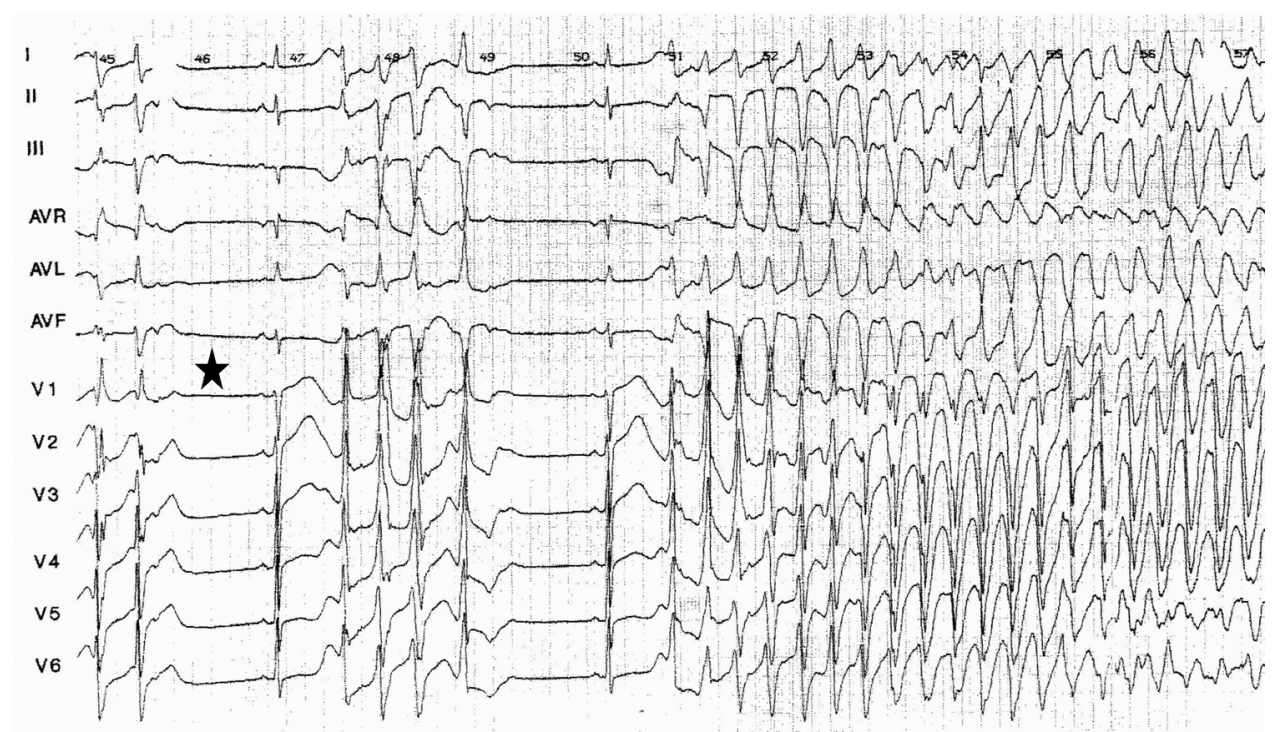

FIG. 2. An example of drug-induced long QT syndrome. A common feature is a pause (often after an ectopic beat) with deranged repolarization in the following cycle. A 12-lead ECG recorded from a 79-year-old patient with advanced heart disease who had recently begun taking dofetilide. The abnormal QT interval is followed by a pause (star) and then four beats of polymorphic ventricular tachycardia (torsades de pointes). Sustained torsades de pointes then occurs after another pause.

Mutations in 13 genes are now recognized as causes of the cLQTS (Curran et al., 1995; Wang et al., 1995a; Schulze-Bahr et al., 1997; Abbott et al., 1999; Plaster et al., 2001; Mohler et al., 2003; Splawski et al., 2004; Vatta et al., 2006) (Medeiros-Domingo et al., 2007; Ueda et al., 2008; Yang et al., 2010) (Table 1). Six of these encode a voltage-gated ion channel, a pore-forming protein that allows passage of specific ions across the cardiac cell membrane as a function of voltage and time during the cardiac cycle, and the remaining seven encode proteins that modulate ion channel function. The identification of these disease genes has led, in turn, to a vastly improved understanding of the role of individual ion currents in control of the cardiac action potential and thus the QT interval on the surface electrocardiogram (ECG) (Fig. 4). It is noteworthy that virtually all drugs that produce diLQTS block one important repolarizing current, $\mathrm{I}_{\mathrm{Kr}}$ (encoded by $\mathrm{KCNH} 2$, formerly termed HERG, the disease gene for type 2 cLQTS), and this finding, in turn, has had important implications for drug development and approval (Roden et al., 1988;
Sanguinetti and Jurkiewicz, 1990; Sanguinetti et al., 1995; Haverkamp et al., 2000; Fenichel et al., 2004).

\section{B. First Drug Associations}

The first drug to be clearly associated with QT interval prolongation and TdP was quinidine, an extract of the cinchona bark. The drug was originally developed as an antimalarial (Frey, 1918), a purpose for which it continues to be used. Indeed, even in the initial use of the drug for a range of infectious diseases (malaria, typhoid fever, scarlet fever) in the 19th century, sudden deaths were reported (Levy, 1922). The drug began to be used for conversion of AF to normal rhythm in the early 20th century by the Dutch cardiologist Wenckebach (1923). In a summary of the first 460 cases reported in the literature, Levy (1922) identified five cases of abrupt syncope or sudden death, just over $1 \%$. He presented a case of a woman with AF treated with quinidine for 6 days, after which normal rhythm was observed; shortly thereafter, the patient developed abrupt loss of consciousness and seizure-like activity; there seems little

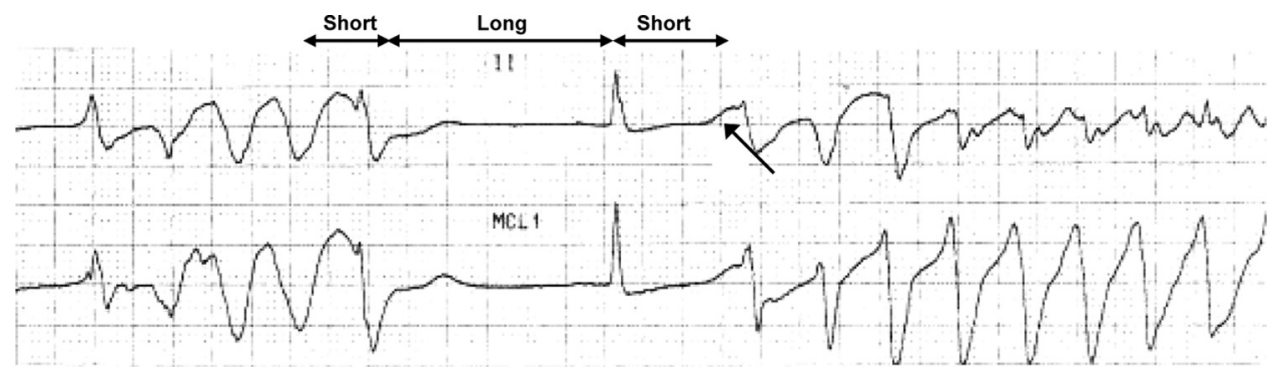

FIG. 3. Rhythm recording from a 70-year-old woman with renal dysfunction recently treated with sotalol for AF. She converted to sinus rhythm

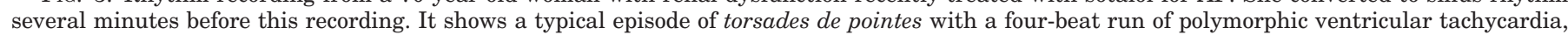

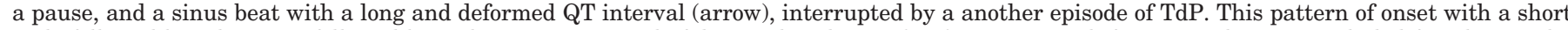

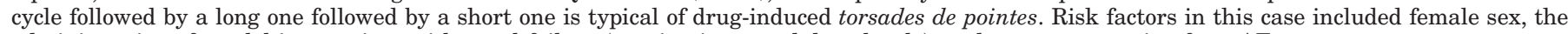
administration of sotalol in a patient with renal failure (causing increased drug levels), and recent conversion from AF. 
TABLE 1

Genes associated with the congenital long QT syndrome

\begin{tabular}{|c|c|c|c|c|c|}
\hline Syndrome & Inheritance & Locus & Ion Channel/Protein & Gene & Frequency in Genotype + LQTS \\
\hline LQT1 & $\mathrm{AD}$ & $11 \mathrm{p} 15$ & $\mathrm{I}_{\mathrm{Ks}}$ & $K C N Q 1$ & $40-55 \%$ \\
\hline LQT2 & $\mathrm{AD}$ & $7 \mathrm{q} 35-\mathrm{q} 36$ & $\mathrm{I}_{\mathrm{Kr}}$ & KCNH2 & $35-45 \%$ \\
\hline LQT3 & $\mathrm{AD}$ & $3 p 21$ & $\mathrm{I}_{\mathrm{Na}}$ & SCN5A & $2-8 \%$ \\
\hline LQT4 & $\mathrm{AD}$ & $4 q 25-q 27$ & Ankyrin B & ANK2 & $<1$ \\
\hline LQT5 & $\mathrm{AD}$ & $21 \mathrm{q} 22$ & $\mathrm{I}_{\mathrm{Ks}}$ & KCNE1 & $<1$ \\
\hline LQT6 & $\mathrm{AD}$ & $21 \mathrm{q} 22$ & $\mathrm{I}_{\mathrm{Kr}}$ & KCNE2 & $<1$ \\
\hline LQT7 & $\mathrm{AD}$ & $17 \mathrm{q} 23$ & $\mathrm{I}_{\mathrm{K} 1}$ & KCNJ2 & $<1$ \\
\hline LQT8 & $\mathrm{AD}$ & $12 \mathrm{p} 13$ & $\mathrm{I}_{\mathrm{Ca}-\mathrm{L}}^{\mathrm{nt}}$ & CACNA1C & $<1$ \\
\hline LQT9 & $\mathrm{AD}$ & $3 p 25$ & Caveolin-3 & CAV3 & $<1$ \\
\hline LQT10 & $\mathrm{AD}$ & $11 q 23$ & $\mathrm{NaV}_{1.5} \beta 4$ & $S C N 4 B$ & $<0.1$ \\
\hline LQT11 & $\mathrm{AD}$ & $7 q 21-7 q 22$ & Yotiao & AKAP9 & $<0.1$ \\
\hline LQT12 & $\mathrm{AD}$ & $20 q 11$ & A1-syntrophin & SNTA1 & $<0.1$ \\
\hline LQT13 & $\mathrm{AD}$ & $11 \mathrm{q} 23-24$ & $\mathrm{I}_{\mathrm{K}-\mathrm{ACh}}$ & KCNJ5 & $<0.1$ \\
\hline JLN1 & $\mathrm{AR}$ & $11 \mathrm{p} 15$ & $\mathrm{I}_{\mathrm{Ks}}$ & $K C N Q 1$ & \\
\hline JLN2 & $\mathrm{AR}$ & $21 \mathrm{q} 22$ & $\mathrm{I}_{\mathrm{Kr}}$ & $K C N E 1$ & \\
\hline
\end{tabular}

$\mathrm{AD}$, autosomal dominant; AR, autosomal recessive; LQT, long QT syndrome; JLN, Jervell and Lange-Nielsen syndrome.

doubt that this represents a case of TdP occurring after conversion from AF to sinus rhythm, as illustrated in Fig. 1 and discussed further below (section V.D).

\section{Torsades de Pointes}

The actual arrhythmia responsible for quinidine syncope was not documented until the advent of online monitoring in the 1960s. In 1964, Selzer and Wray (1964) identified "paroxysmal ventricular fibrillation" in eight patients with quinidine syncope; a review of the published tracings shows typical episodes of what we would now call quinidine-associated marked QT prolongation and TdP, although no specific mention of the QT interval was made at the time (Selzer and Wray, 1964).

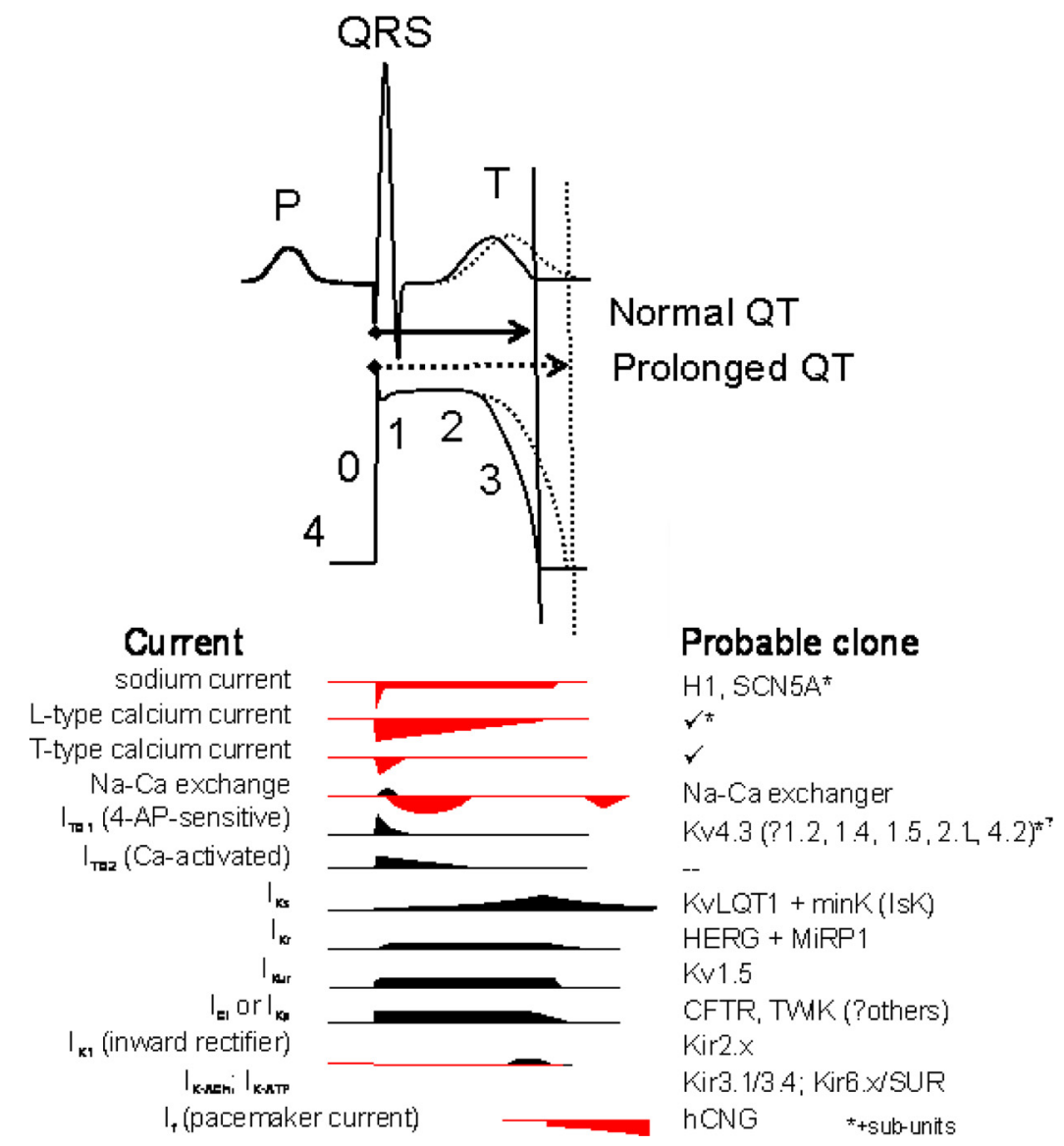

FIG. 4. The relationship between ionic currents and the duration of cardiac repolarization recorded from the ECG and the myocardial action potential. Top, idealized ECG recording aligned with a schematized ventricular myocyte action potential. A balance between inward (red) and outward (black) currents controls repolarization, and a relative increase of outward over inward currents drives repolarization to completion. The action potential is initiated by inward sodium current (phase 0) and proceeds through early (phases 1 and 2) and late (phase 3 ) stages of repolarization. Increases in net inward current prolong repolarization. The "plateau" phases (2 and 3$)$ are vulnerable to minor increases in net inward current, which can initiate early afterdepolarizations that are one likely cause of torsades de pointes LQTS. [Adapted from Anderson ME, Darbar D and Kannankeril P (2007) Genetics of arrhythmias, in Textbook of Cardiovascular Medicine (Topol EJ ed), Lippincott Williams \& Wilkins, Philadelphia, PA. Copyright (c) 2007 Lippincott Williams \& Wilkins. Used with permission.] 
As discussed further below, antiarrhythmic drugs with QT interval prolonging potential carry a 1 to $3 \%$ risk of TdP over 1 to 2 years of exposure (Soyka et al., 1990; Hohnloser et al., 1995; Torp-Pedersen et al., 1999), with the exception of amiodarone.

diLQTS also occurs with drugs not prescribed for cardiovascular indications, and the incidence seems orders of magnitude lower. The first such "noncardiovascular" drugs to be implicated in QT prolongation and TdP (now obvious from published reports) were antipsychotic agents, specifically thioridazine (Hollister and Kosek, 1965; Giles and Modlin, 1968). Since the 1960s, diLQTS has been reported with dozens of marketed noncardiovascular drugs in many therapeutic categories (Table 2; an up-to-date list is maintained at http://www.torsades. org). Although the idea that noncardiovascular drugs could also prolong the QT interval and trigger TdP or even sudden death was recognized during the 1970s and 1980 s, it remained an electrocardiographic curiosity until the initial report of terfenadine-associated TdP in the late 1980s (Monahan et al., 1990). Terfenadine was so widely used that it was being considered for over-the-

TABLE 2

Drugs well-recognized to cause torsades de pointes

A listing of drugs and the strength of their association with torsades de pointes is maintained at http://www.torsades.org.

\begin{tabular}{l}
\hline Antiarrhythmics \\
Amiodarone \\
Disopyramide \\
Dofetilide \\
Ibutilide \\
Procainamide \\
Quinidine \\
Sotalol \\
Antibiotics \\
Chloroquine \\
Clarithromycin \\
Erythromycin \\
Halofantrine \\
Pentamidine \\
Sparfloxacin \\
Antipsychotics \\
Chlorpromazine \\
Haloperidol \\
Mesoridazine ${ }^{a}$ \\
Pimozide \\
Thioridazine \\
Antinauseants \\
Domperidone \\
Droperidol \\
Antineoplastic \\
Arsenic trioxide \\
Calcium channel blockers \\
Bepridil \\
Lidoflazine \\
Gastric promotility \\
Cisapride \\
Opiates \\
Methadone \\
Levomethadyl \\
Antihistamines \\
Terfenadine \\
Astemizole \\
\hline \\
\hline \\
Not avalabe in \\
\hline
\end{tabular}

${ }^{a}$ Not available in the United States. counter status at the time, so the recognition of this rare serious adverse event was an initiator for the regulatory and drug development issues discussed below.

\section{Initial Mechanistic Insights}

The French cardiologist Dessertenne (1966) coined the term "torsades de pointes" in his description of a polymorphic ventricular tachycardia with a slowly undulating electrical axis that he had observed in an elderly woman with advanced atrioventricular block. By 1970, Dessertenne and colleagues (Motté et al., 1970) provided a summary of their view of $\mathrm{TdP}$, the main points of which remain valid: the arrhythmia is often self-limited but can degenerate to true ventricular fibrillation; the heart rate before the development of an event is often slow; and multiple etiologies have been recognized, including atrioventricular block, hypokalemia, and "intolerance" to quinidine. They noted the existence of a congenital syndrome of QT prolongation and speculated that TdP was also responsible for syncope in that entity. They described the salutary effect of normalizing the serum potassium and of increasing the heart rate by administration of isoproterenol or placement of a pacemaker, maneuvers that remain standard therapy for diLQTS to this day. They noted that many patients developing TdP were also taking digitalis glycosides but were uncertain of the potential role of digitalis toxicity to the arrhythmia. Contemporary studies suggest that intracellular calcium overload, the key effect of excess digitalis, can increase the risk for diLQTS (Burashnikov and Antzelevitch, 1998; Wu et al., 1999).

Two key clinical features of diLQTS are hypokalemia and slow underlying heart rates. Accordingly, investigators have sought to characterize the effects of known QT prolonging agents on cardiac tissues under these conditions. One of the earliest reports identified early afterdepolarizations (EADs) in dog Purkinje fibers exposed to high concentrations of sotalol and paced slowly (Strauss et al., 1970). A similar finding was reported with the procainamide metabolite $N$-acetylprocainamide (Dangman and Hoffman, 1981), and clinical trials of NAPA identified QT prolongation and diLQTS as a risk (Olshansky et al., 1982; Chow et al., 1984). In the mid-1980s, bradycardia-dependent EADs were reported with quinidine exposure in canine Purkinje fibers, and this was potentiated when extracellular potassium was lowered (Roden and Hoffman, 1985). Thus, an initial hypothesis was that bradycardia and hypokalemia lead to marked action potential prolongation and EADs in conduction tissue and that these serve as initiators of TdP, as discussed further below.

\section{Molecular Mechanisms}

The molecular mechanisms underlying the diLQTS have been greatly informed by studies of the cLQTS, in which mutations resulting in abnormal cardiac ion 
channel function result in the phenotype of QT prolongation and risk for sudden death due to TdP. Furthermore, a number of model systems have been helpful in elucidating underlying mechanisms, including cellular, tissue, whole-organ, and whole-animal models (Table 3).

\section{A. Congenital Long QT Syndrome Informing the More Common Drug-Induced Long QT Syndrome}

The precise genetic basis in cases of the cLQTS was first established in the 1990s with the identification of causative mutations in genes that encode proteins that form cardiac ion channels. Contemporary genetic testing identifies mutations in more than $80 \%$ of affected patients, and the two most common forms (responsible for 85-90\% of genotype-positive cases) result from loss-offunction mutations in KCNQ1 (LQT1) and KCNH2 (LQT2) (Curran et al., 1995; Wang et al., 1996). These genes encode the $\alpha$ subunits of the major repolarizing potassium channels, which underlie the currents $\mathrm{I}_{\mathrm{Ks}}$ and $\mathrm{I}_{\mathrm{Kr}}$. Mutations in genes that encode function-modifying or $\beta$-subunits, KCNE1 (LQT5) and KCNE2 (LQT6), also reduce $\mathrm{I}_{\mathrm{Ks}}$ and $\mathrm{I}_{\mathrm{Kr}}$ and result in cLQTS (Splawski et al., 1997; Abbott et al., 1999). Mutations in the $\beta$ subunit KCNE3 have been identified in isolated patients with LQTS, and this may represent another form (Ohno et al., 2009). For KCNE2 and $\mathrm{KCNE} 3$, the evidence for causation in the congenital syndrome is weak, because only isolated patients and not families have been reported. Another nonion channel gene implicated in cLQTS is AKAP9, which encodes the protein kinase $A$ adaptor protein yotiao and probably reduces $\mathrm{I}_{\mathrm{Ks}}$ (Chen et al., 2007). Mutations in these genes can result in "loss of function" by several mechanisms, including altered expression of channel proteins, expression of nonfunctional or dysfunctional proteins, or expression of proteins that can function normally but are not processed to the cell membrane normally (altered trafficking) (Furutani et al., 1999).

The other major form of the congenital syndrome (10$15 \%$ of genotype-positive cases) is LQT3, in which pa- tients carry mutations in SCN5A, the gene that encodes the $\alpha$ subunit of the cardiac sodium channel and that underlies $\mathrm{I}_{\mathrm{Na}}$, the cardiac sodium current (Wang et al., 1995b). The mutations generally result in defective fast inactivation and thus augmented sodium current late during the action potential when the channel would ordinarily have fully inactivated (Fig. 4). In addition, mutations in genes encoding proteins that interact with the cardiac sodium have also been reported in cLQTS. A mutation in the sodium channel $\beta$-subunit $S C N 4 B$ has been reported in a single patient with cLQTS (MedeirosDomingo et al., 2007). Mutations in nonion channel genes CAV3 and SNTA1 have been reported in patients with a LQT3-like phenotype, and indeed these mutations seem to alter sodium current in a similar fashion as described above (Vatta et al., 2006; Ueda et al., 2008).

Mutations in other ion channel genes, KCNJ2 and CACNA1C, have been associated with $\mathrm{QT}$ prolongation and TdP, as well as significant extracardiac phenotypes (Plaster et al., 2001; Splawski et al., 2004). LQT4 has been linked to mutations in $A N K 2$, which encodes a structural protein that, when mutated, results in altered localization and expression of ion channels (Mohler et al., 2003). Patients with ANK2 mutations do not uniformly have prolonged QT intervals, and it has been suggested that LQT4 be renamed "sick sinus syndrome associated with bradycardia" or "ankyrin-B syndrome" (Mohler et al., 2007).

\section{B. Mechanisms of QT Prolongation in the Drug-Induced Long QT Syndrome}

As summarized above, cLQTS may result from mutations that disrupt any number of ion currents, including $\mathrm{I}_{\mathrm{Ks}}, \mathrm{I}_{\mathrm{Kr}}$, and $\mathrm{I}_{\mathrm{Na}}$. In contrast, the mechanism by which drugs cause acquired LQTS is almost always block of the rapid component of the delayed rectifier potassium current, $\mathrm{I}_{\mathrm{Kr}}$ (Roden and Viswanathan, 2005). This KCNH2 channel is blocked by drugs with diverse structures en-

TABLE 3

Models to study the potential for drug-induced torsades de pointes

\begin{tabular}{|c|c|c|c|}
\hline Model & Initial Descriptions by & Advantages & Disadvantages \\
\hline $\begin{array}{l}\text { Block of heterologously expressed } \\
\text { KCNH2 current }\end{array}$ & Snyders and Chaudhary, 1996 & $\begin{array}{l}\text { Dose-response relationship for potential } \\
\text { arrhythmogenic effects can be } \\
\text { defined; high throughput is feasible; } \\
\text { relatively inexpensive }\end{array}$ & $\begin{array}{l}\text { No relationship to arrhythmias; effects on other } \\
\text { currents (e.g., sodium or L-type calcium) not } \\
\text { taken into account }\end{array}$ \\
\hline Block of $\mathrm{I}_{\mathrm{Kr}}$ in cardiomyocytes & Sanguinetti and Jurkiewicz, 1990 & $\begin{array}{l}\text { Dose-response relationship for potential } \\
\text { arrhythmogenic effects can be } \\
\text { defined. }\end{array}$ & $\begin{array}{l}\text { No relationship to arrhythmias; effects on other } \\
\text { currents (e.g., sodium or L-type calcium) not } \\
\text { taken into account; myocyte preparation may } \\
\text { not be uniform }\end{array}$ \\
\hline $\begin{array}{l}\text { Action potential prolongation in } \\
\text { canine (or rabbit) Purkinje } \\
\text { fibers }\end{array}$ & $\begin{array}{l}\text { Dangman and Hoffman, 1981; } \\
\text { Roden and Hoffman, } 1985\end{array}$ & Arrhythmogenic EADs can be elicited & $\begin{array}{l}\text { Canine repolarization may differ from that in } \\
\text { humans; drug effects may be greater in } \\
\text { isolated fibers than in whole heart }\end{array}$ \\
\hline $\begin{array}{l}\text { Perfused canine left ventricular } \\
\text { "wedge" preparation }\end{array}$ & $\begin{array}{l}\text { Strauss et al., 1970; Antzelevitch } \\
\quad \text { et al., } 1991 \text { Yan et al., } 1998\end{array}$ & $\begin{array}{l}\text { Enables mechanistic studies of the } \\
\text { arrhythmia; allows evaluation of } \\
\text { multiple cell types to the arrhythmia }\end{array}$ & $\begin{array}{l}\text { Complex, low throughput; role of } \mathrm{M} \text { cells is } \\
\text { disputed }\end{array}$ \\
\hline $\begin{array}{l}\text { Isolated perfused female rabbit } \\
\text { hearts }\end{array}$ & Hondeghem and Hoffmann, 2003 & $\begin{array}{l}\text { Validated across large numbers of } \\
\text { drugs; may be able to identify agents } \\
\text { with arrhythmogenic potential even } \\
\text { without marked QT prolongation }\end{array}$ & $\begin{array}{l}\text { Complex, low throughput, although automated } \\
\text { methods have been developed }\end{array}$ \\
\hline $\begin{array}{l}\text { Anesthetized methoxamine- } \\
\text { treated rabbits }\end{array}$ & Carlsson et al., 1990 & $\begin{array}{l}\text { Simple whole-heart model; } \\
\text { methoxamine required although role } \\
\text { uncertain }\end{array}$ & Complex, low throughput \\
\hline $\begin{array}{l}\text { Dogs with long-term } \\
\text { atrioventricular block }\end{array}$ & $\begin{array}{l}\text { Chézalviel-Guilbert et al., 1995; } \\
\text { Vos et al., } 1998\end{array}$ & $\begin{array}{l}\text { Enables mechanistic studies of the } \\
\text { arrhythmia; studies of mechanisms } \\
\text { over time in the whole heart }\end{array}$ & Complex, low throughput \\
\hline
\end{tabular}


compassing many different drug classes, including antiarrhythmics, antipsychotics, antibiotics, and antihistamines (Table 2). Despite the important roles of other potassium (and sodium) channels in the cLQTS, these channels are far less susceptible to block by drugs.

Drugs block the KCNH2 channel from its inner mouth and two structural features unique to this channel probably explain why it is particularly susceptible to block (Mitcheson et al., 2000). First, the presence of two polar amino acids (Thr623 and Ser624) in the pore region and two aromatic amino acids (Tyr652 and Phe656) with side chains oriented toward the large central cavity of the pore region provide high-affinity binding sites for a wide range of compounds. Introducing mutations at these sites reduces binding affinity of multiple drugs. The amino acids Thr623 and Ser624 are highly conserved across voltage-dependent potassium channels and thus would not explain why $\mathrm{KCNH} 2$ is principally susceptible to drug block. In contrast, Tyr652 and Phe656 are not conserved-most potassium channels have an Ile and a Val in homologous positions. The presence of aromatic side chains in these positions seems to accommodate multiple interactions explaining the surprising chemical diversity of KCNH2 blockers. Second, most potassium channels contain two proline residues in the helix that forms part of the pore, restricting access to the drug binding site. The absence of these two prolines in KCNH2 is thought to allow the pore to accommodate bulky channel blockers. Mutation of these residues to the Pro-Val-Pro seen in other potassium channels results in reduced drug binding (Fernandez et al., 2004).

Although these structural peculiarities explain why KCNH2 channels are more prone to direct block by a wide array of drugs, additional mechanisms have been described that can contribute to $\mathrm{QT}$ prolongation by drug, although their contribution to the syndrome in patients remains uncertain. Disruption of KCNH2 protein trafficking to the cell surface by a drug was first demonstrated with the antineoplastic agent arsenic trioxide (Ficker et al., 2004). Subsequently, pentamidine, another drug known to cause diLQTS (Table 2), was found to block $\mathrm{I}_{\mathrm{Kr}}$ but only at concentrations several hundred-fold higher than therapeutic levels (Cordes et al., 2005). With prolonged exposure to pentamidine at therapeutic levels, KCNH2 channel protein trafficking is disrupted resulting in reduced cell surface expression of otherwise functional channels (Kuryshev et al., 2005). The cholesterol-lowering drug probucol was also found to disrupt trafficking, but, in this case, without direct channel block (Guo et al., 2007). Fluoxetine and norfluoxetine have also been shown to block KCNH2 channels and disrupt trafficking. It is noteworthy that mutation of the Phe656 to alanine or cysteine reduced channel block by drug (as expected) but did not alter fluoxetinemediated disruption of channel protein trafficking.
These findings suggest that disruption of protein trafficking is mediated by drug binding to a different site on the channel or to a different protein in the secretory pathway (Rajamani et al., 2006). This loss of function by disruption of protein trafficking, rather than by production of channels that reach the cell membrane but do not conduct current, has been recognized as a relatively common mechanism in cLQTS caused by $\mathrm{KCNH} 2$ mutations (Anderson et al., 2006).

The finding of reduced protein trafficking as a common mechanism in some instances of both congenital and diLQTS raises the possibility of pharmacologic "rescue" of misprocessed channels, which function normally when in the cell membrane. Certain agents have the ability to restore cell surface expression of misprocessed channels. Ironically, agents that rescue misprocessed channels generally also result in channel block, with few exceptions (Rajamani et al., 2002). Pharmacologic "rescue" may also have deleterious effects, and has been demonstrated as a mechanism resulting in a diLQTS phenotype. The SCN5A mutation L1825P studied in a heterologous expression system results in augmented late sodium current, typical of congenital LQT3 (Liu et al., 2005a). The individual with the mutation had a normal QT interval at baseline, but developed QT prolongation and $\mathrm{TdP}$ with cisapride. Follow-up studies revealed that the mutant sodium channel protein did not reach the cell surface, thus no abnormal phenotype was evident at baseline. Cisapride administration resulted in the LQT phenotype by "rescue" of the abnormal $S C N 5 A$ protein, in addition to $\mathrm{I}_{\mathrm{Kr}}$ block.

Yet another example of a novel mechanism underlying diLQTS is found in antiprotozoal agents containing antimony, which do not seem to affect $\mathrm{I}_{\mathrm{Kr}}$, but increase calcium currents, resulting in a prolonged QT (Kuryshev et al., 2006). In addition, enhanced sodium current has been reported with a single drug that delays sodium channel inactivation, with QT prolongation and TdP (Kuhlkamp et al., 2003). These examples underscore the complexity of the mechanisms underlying drug-induced QT prolongation.

\section{Mechanisms of Proarrhythmia in the Setting of QT Prolongation}

The development of TdP is inevitably accompanied by QT interval prolongation. Sometimes, this is evident in each heartbeat, and sometimes it occurs only in the beat or two before the arrhythmia, often at the end of a short-long-short set of cycle length changes described in section V.B (see Figs. 1-3). Therefore, mechanisms are required to link long QT intervals-or long action potential durations at the level of single cells-and susceptibility to this arrhythmia. Because excessive QT prolongation is associated with increased risk for $\mathrm{TdP}$, the identification of $\mathrm{I}_{\mathrm{Kr}}$ block as a common mechanism underlying drug-induced QT prolongation offers an attractive prospect of a simple method to identify agents with 
risk. Unfortunately, screening drugs purely for $\mathrm{I}_{\mathrm{Kr}}$ block is confounded by the lack of a straightforward relationship among $\mathrm{I}_{\mathrm{Kr}}$ block, degree of QT prolongation, and risk for TdP. For example, the antiarrhythmic agent verapamil blocks $\mathrm{I}_{\mathrm{Kr}}$ but does not prolong the QT interval and is not associated with TdP (Yang et al., 2001), probably reflecting its potent block of L-type calcium channels. Likewise, ranolazine is an $\mathrm{I}_{\mathrm{Kr}}$ blocker but in fact prevents experimental TdP despite prolongation of the action potential; this is thought to be because the drug also blocks sodium current during the plateau of the action potential (Wu et al., 2006). Thus, $\mathrm{I}_{\mathrm{Kr}}$ block alone is not sufficient to result in TdP.

Further, clinical studies make it clear that QT prolongation alone is also insufficient to generate TdP. The antiarrhythmic drug amiodarone and the anesthetic agent sodium pentobarbital both result in QT prolongation, but TdP caused by amiodarone is exceedingly rare (Lazzara, 1989), and sodium pentobarbital probably reduces the risk of TdP (Shimizu et al., 1999). In addition, some drugs may cause polymorphic ventricular tachycardia without QT prolongation, which, by definition, are not labeled TdP, but the proarrhythmic mechanisms may be similar and the distinction between these incidents and diLQTS is not always clear (Shah and Hondeghem, 2005).

In experimental settings, prolongation of repolarization in Purkinje fibers or in some myocardial cells can lead to the development of EADs, oscillations in the membrane potential during repolarization (Fig. 5). EADs represent inward current and are thought to result from reopening of either L-type calcium channels or sodium channels or from current generated via augmented sodium-calcium exchange, and they may result in ectopic beats if the amplitude of the EAD reaches a critical threshold and occurs in a large enough region of the heart (January and Riddle, 1989). Triggered upstrokes from EADs in tissue in which repolarization is sufficiently disturbed is the likely initiating mechanism for TdP. Thus, drug-induced proarrhythmia results in-

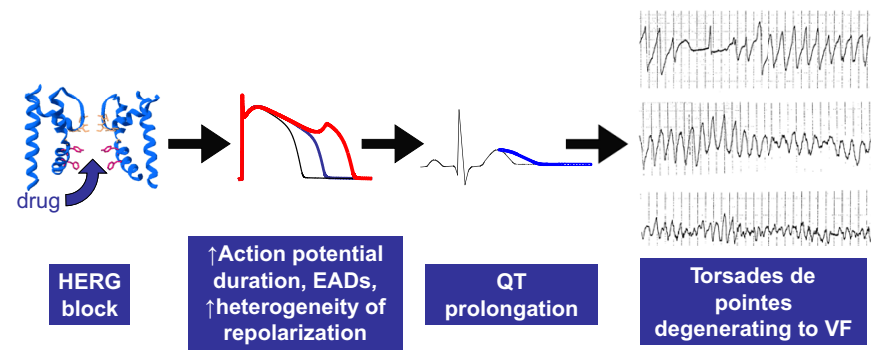

FIG. 5. Mechanisms of proarrhythmia associated with human etherà-go-go-related gene (HERG) channel blockade. Blockade of the HERG channel produces prolongation of the QT interval (blue) and generates an $\mathrm{EAD}$ (red) in the cardiac action potential. These changes, which are heterogeneous across the ventricular wall, create a substrate for TdP. In this example, torsades de pointes degenerates into ventricular fibrillation. [Adapted from Roden DM and Viswanathan PC (2005) Genetics of acquired long QT syndrome. J Clin Invest 115:2025-2032. Copyright (C) 2005 American Society for Clinical Investigation. Used with permission.] directly from $\mathrm{I}_{\mathrm{Kr}}$ block, which enables activation or reactivation of inward currents underlying EADs. This partly explains why verapamil rarely causes TdP: even though it is a potent $I_{\mathrm{Kr}}$ blocker (Zhang et al., 1999), it also reduces EADs by blocking inward calcium current (Shimizu et al., 1995). Furthermore, verapamil shortens QT interval, reduces EADs, and lowers the incidence of TdP in a model of acquired LQTS by a combination of $\mathrm{I}_{\mathrm{Ks}}$ and $\mathrm{I}_{\mathrm{Kr}}$ block (Aiba et al., 2005).

Studies in multicellular preparations such as the whole heart or the wedge described below have described mechanisms responsible for maintenance of the arrhythmia after its initiation. Studies in the wedge have emphasized the role of heterogeneity of action potential durations as a mechanism contributing to maintenance of the arrhythmia by promoting re-entrant excitation (Antzelevitch, 2008).

\section{Reduced Repolarization Reserve}

A unifying framework to understand diLQTS is the concept of "reduced repolarization reserve" (Roden, 1998, 2008; Roden and Yang, 2005) (Fig. 6). This concept suggests that multiple often-redundant mechanisms maintain normal repolarization, so minor alterations in function may not be obvious at baseline. Thus, for example, a minor reduction in repolarizing current (e.g., as a result of a genetic lesion resulting in a small reduction in an important repolarizing ion channel) may be without consequence because other mechanisms come into play to maintain a near-normal QT interval. However, such reduced reserve may become obvious when further stressors to repolarization, such as drug challenge, slow heart rates, or hypokalemia are superimposed. This framework is a specific example of the more general concept that complex biologic systems rarely break down because of single lesions (genetic or acquired).

The specific nature of repolarization reserve and how it might be reduced has been investigated, and a leading candidate mechanism seems to be loss of $\mathrm{I}_{\mathrm{Ks}}$ function. This makes intuitive sense, because reduction in $\mathrm{I}_{\mathrm{Ks}}$ might be without consequence as long as a robust $\mathrm{I}_{\mathrm{Kr}}$ is present; in this situation, however, $\mathrm{I}_{\mathrm{Kr}}$ block may result in catastrophic failure to maintain normal repolarization and thus TdP. Human ventricular myocytes display resistance to action prolongation with $\mathrm{I}_{\mathrm{Kr}}$ block when $\mathrm{I}_{\mathrm{Ks}}$ is stimulated (Jost et al., 2005) (Fig. 7). In a simulation study, Silva and Rudy (2005) suggested that $I_{\mathrm{Ks}}$ gating properties were ideally suited to meet such a reserve function. One especially intriguing observation is that exposure to some QT-prolonging drugs can down-regulate $\mathrm{I}_{\mathrm{Ks}}$ by stimulating a microRNA (Xiao et al., 2008); this in turn suggests that repolarization reserve may be dynamic and itself regulated by drug exposures. Finally, genomic approaches discussed below implicate $\mathrm{I}_{\mathrm{Ks}}$ alleles in risk for drug-induced TdP. 


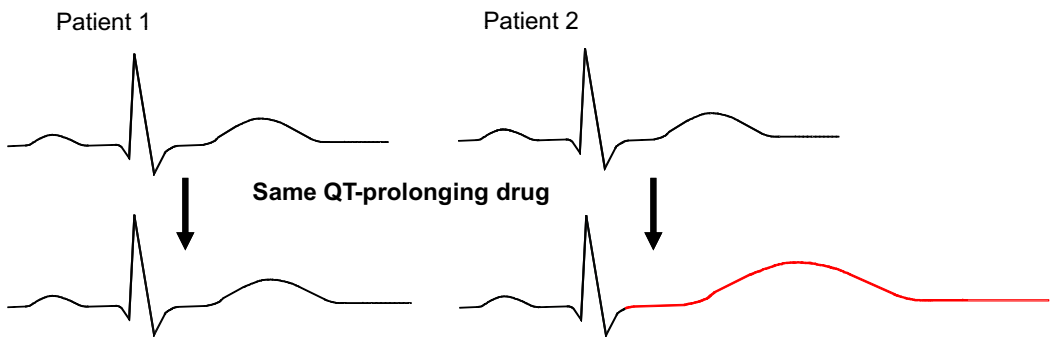

FIG. 6. The concept of reduced repolarization reserve. Patient 1 is prescribed a QT-prolonging drug and has minimal or no prolongation of the QT interval. In contrast, patient 2, given the same QT-prolonging drug at the same dosage, develops marked prolongation of the QT interval. This has been termed "reduced repolarization reserve" and as discussed further in section III.D, repolarization is a physiologically redundant process such that $\mathrm{I}_{\mathrm{Kr}}$ block will not result in markedly prolonged repolarization; that is, the system displays some "reserve." However, otherwise subclinical lesions in other components of the repolarization system, such as reduction of $\mathrm{I}_{\mathrm{Ks}}$ as a result of genetic factors or hypokalemia, may become apparent as marked QT prolongation when $\mathrm{I}_{\mathrm{Kr}}$ is reduced.

\section{Models of Drug-Induced Long QT Syndrome}

A number of laboratories have developed model systems in which TdP mechanisms have been further explored. These include the perfused canine left ventricular "wedge" preparation (Antzelevitch et al., 1991; Yan et al., 1998); dogs in which the atrioventricular (AV) node has been destroyed to cause chronic AV block (Chézalviel-Guilbert et al., 1995; Vos et al., 1998), anesthetized methoxamine-treated rabbits (Carlsson et al., 1990), and isolated perfused female rabbit hearts (Hondeghem and Hoffmann, 2003). In each of these settings, administration of a known $\mathrm{I}_{\mathrm{Kr}}$-blocking agent can result in marked action potential prolongation, QT prolongation and deformity, and sustained polymorphic arrhythmias. Mapping studies have suggested either re-

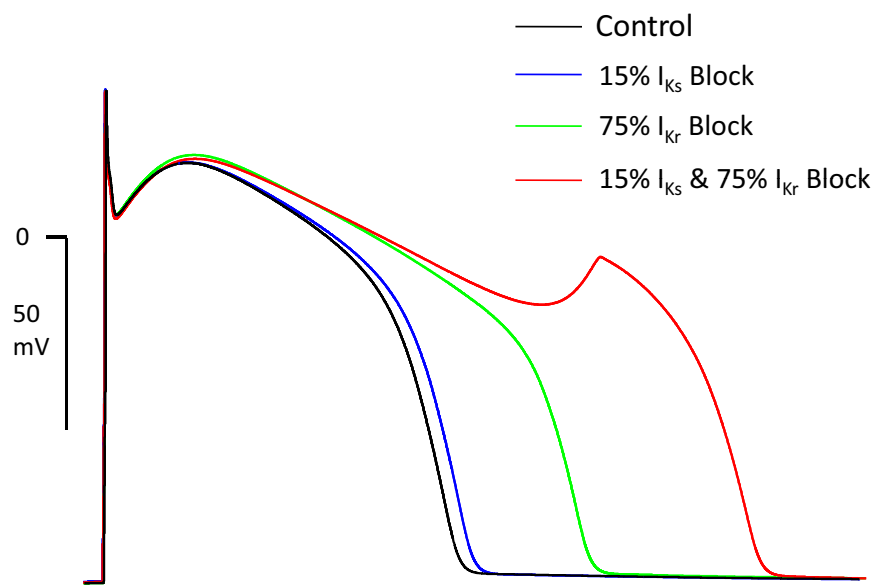

$100 \mathrm{~ms}$

FIG. 7. Luo Rudy simulations showing the concept of repolarization reserve. The blue line shows the effect of reducing $\mathrm{I}_{\mathrm{Kr}}$ by $15 \%$, as might be expected in a subtle congenital long QT syndrome mutation. The green line shows the expected prolongation of the control action potential resulting from $75 \% \mathrm{I}_{\mathrm{Kr}}$ blockade. The red line shows the effect of the same degree of drug blockade applied to the simulation with $15 \% \mathrm{I}_{\mathrm{Ks}}$ blockade. Not only is there marked exaggeration of action potential prolongation, but an EAD with a triggered upstroke is also generated; L-type calcium current generates the upstroke in this model. [Reprinted from Roden DM and Viswanathan PC (2005) Genetics of acquired long QT syndrome. J Clin Invest 115:2025-2032. Copyright (C) 2005 American Society for Clinical Investigation. Used with permission.] petitive EADs or re-entry due to heterogeneity of action potential durations-not mutually exclusive-as the underlying mechanism for the arrhythmia (El-Sherif et al., 1999).

In the wedge preparation, Antzelevitch and coworkers (Antzelevitch and Sicouri, 1994; Yan et al., 1998; Weissenburger et al., 2000; Antzelevitch and Fish, 2001) have identified a layer of cells in the midmyocardium, termed $\mathrm{M}$ cells, that have especially long action potentials and are especially prone to action potential prolongation under TdP-eliciting conditions. Others, however, have disputed the role of $\mathrm{M}$ cells, and even their existence, in the intact heart (Opthof et al., 2007). The studies in the AV-blocked dog have shown that immediately after AV nodal blockade is established, action potentials and QT intervals are long and then proceed to lengthen even further over time. This finding suggests that not only slow rates but also electrophysiologic "remodeling" (a chronic change in response to slow heart rates) predisposes to TdP (Vos et al., 1998, 2000).

\section{A. Studying $I_{K r}$ in Cellular Systems}

Because virtually all drugs that prolong the QT interval are $\mathrm{I}_{\mathrm{Kr}}$ blockers, it is also routine to test new drug candidates for $\mathrm{I}_{\mathrm{Kr}}$-blocking activity. Details of how this is accomplished (e.g., specific cellular models, temperature, pacing protocols, etc.) may modulate the result (Hammond and Pollard, 2005; Bowlby et al., 2008; Hancox et al., 2008). Ion channel studies in single cells are the simplest for the prediction of drug-induced torsades de pointes, and some can be performed by automated, high-throughput systems (Nattel et al., 2008). These relatively inexpensive studies are typically performed early in the drug development process, at times allowing the developer to select certain compounds from a wide array of candidates for further development. The use of cardiac myocytes for evaluation of $\mathrm{I}_{\mathrm{Kr}}$ block guarantees that the channel is present with any naturally occurring subunits or other intracellular factors that may modulate channel activity. However, the use of myocytes poses technical difficulties, including the need to isolate fresh cells with each experiment and possible overlap of the current of interest with other ion currents. Further- 
more, the magnitude and occasionally the gating of $\mathrm{I}_{\mathrm{Kr}}$ varies among species.

Thus, noncardiac mammalian cells transfected with DNA to express human ion channels are often used for these studies because of their ease of maintenance in culture and ease of high-resistance seal formation with microelectrodes. Another advantage of these heterologous expression systems is the lack of interference from currents other than the one of interest, although ancillary proteins-whose expression may vary among cell types - have been reported to affect the potency or kinetics of $I_{K r}$ block (Panaghie and Abbott, 2006). The most frequently used cells are human embryonic kidney and Chinese hamster ovary cells. For studies of $\mathrm{I}_{\mathrm{Kr}}$, transfection with KCNH2 cDNA alone or cotransfection with cDNA encoding the ancillary KCNE2 protein can be performed. An alternative to mammalian cells occasionally used are Xenopus laevis oocytes injected with KCNH2 cDNA. The drug concentrations that achieve channel-blocking effects in these cells are generally much greater than in other preparations, making it difficult to integrate results obtained in $X$. laevis oocytes with the results of other studies.

Certain technical factors that pertain to the study of drug effects on $\mathrm{I}_{\mathrm{Kr}}$ deserve mention. During the experiment, the cells of the preparation may slowly lose their viability, with an observed decline in all of the current amplitudes. These declines become especially critical for the study of drugs that slowly penetrate cells or that exert their effects on the intracellular side of the channel, as most $\mathrm{I}_{\mathrm{Kr}}$ blockers do. One method commonly used to slow the rates of these declines is to work with the preparation at room temperature rather than physiologic temperature; however, the degree of drug block derived at room temperature may differ from that derived at physiologic temperature by almost an order of magnitude. In addition, many drugs block channels in a frequency-dependent manner, which may translate into a heart rate-dependent change in QT interval. Most $\mathrm{I}_{\mathrm{Kr}}$ blockers display "reverse use-dependence" with greater block at slower heart rates; thus, it is useful to determine channel block at various frequencies (Dorian, 2000).

\section{B. Wedge and Isolated Heart Preparations}

The above methods are widely used, relatively inexpensive, simple screening tests for $\mathrm{I}_{\mathrm{Kr}}$ block, but the poor correlation between $\mathrm{I}_{\mathrm{Kr}}$ block, degree of $\mathrm{QT}$ prolongation, and risk for $\mathrm{TdP}$ has led to more complex methods of predicting arrhythmogenic risk from drugs. Studies in Purkinje fibers (described in section II.C), the ventricular wedge preparation, and the Langendorff-perfused isolated heart, although more complicated than the single-cell studies above, offer the advantages of being able to observe action potential or QT prolongation and TdP directly in the model itself.
1. Ventricular Wedge Preparation. The arterially perfused ventricular wedge preparation was developed in the mid-1990s using canine left ventricle to study the electrical heterogeneity of ventricular myocardium in intact tissue (Yan and Antzelevitch, 1996). In the canine ventricular wedge, three distinct cell types (epicardial, endocardial, and $\mathrm{M}$ cells), distinguished by their action potentials (Yan et al., 1998), have been described. M cells have the longest action potential duration and increased sensitivity to prolong the action potential in response to the slowing of the rate and upon exposure of drugs that prolong the action potential. This effect is thought to reflect either reduced $\mathrm{I}_{\mathrm{Ks}}$ or enhanced inward plateau $\mathrm{I}_{\mathrm{Na}}$ in $\mathrm{M}$ cells compared with other cell types (Liu and Antzelevitch, 1995; Zygmunt et al., 2001). Currently, dog left ventricle is the predominant wedge preparation used to study drug-induced $\mathrm{TdP}$, although rabbit is also used. Wedge preparations from rabbits differ from the canine wedge, in that the entire endocardium resembles $\mathrm{M}$ cells in terms of electrophysiologic properties, and there is no intramural region of longest action potential (Yan et al., 2001). The experimental preparation involves cannulating a coronary artery of an excised heart and perfusing it with cardioplegic solution. Unperfused areas of the ventricle are removed, and the wedge studied in a tissue bath while arterially perfused, with pressure monitoring. A transmural pseudo-ECG signal can be recorded with extracellular electrodes placed near the epicardial and the endocardial surfaces, and action potentials are recorded simultaneously from the epicardial and endocardial regions with intracellular floating microelectrodes.

In the rabbit wedge preparation, the end of repolarization of the epicardial cells coincides with the peak of the $\mathrm{T}$ wave and the end of repolarization of the endocardial cells ( $\mathrm{M}$ cells in the canine wedge) coincides with the end of the $\mathrm{T}$ wave on the pseudo-ECG. It has been reported that the interval from the peak to the end of $\mathrm{T}$ wave (Tp-Te) correlates with transmural dispersion of repolarization (TDR) (Yan et al., 1998). When QT-prolonging drugs are infused into the wedge preparation, they typically cause preferential prolongation of the action potential duration of endocardial cells or $\mathrm{M}$ cells, leading to increased TDR and prolongation of the Tp-Te interval on the pseudo-ECG. The Tp-Te is often "normalized" to the QT by calculating the Tp-Te/QT, to increase the sensitivity of delayed terminal repolarization. Increased TDR is postulated to contribute to the development of TdP by increasing the vulnerable window during repolarization, facilitating propagation of EADs. In addition to prolongation of QT interval and $\mathrm{Tp}-\mathrm{Te} / \mathrm{QT}$, EADs and TdP can be directly observed in the wedge preparation, and a scoring system incorporating each of these markers has been proposed (Wang et al., 2008). Using this quantitative system, eight compounds with known ability to prolong QT or produce TdP and five with established safety were studied in a blinded fashion. Compounds with known risk of TdP showed a sig- 
nificant increase in $\mathrm{QT}, \mathrm{Tp}-\mathrm{Te}, \mathrm{Tp}-\mathrm{Te} / \mathrm{QT}$ ratio, and incidence of EADs and TdP compared with the negative compounds. The scores of safe drugs at concentrations up to 100 times greater than that of the free plasma concentration were very low $(\leq 0.25)$, whereas drugs known to prolong the QT and cause TdP received scores ranging from 1.00 to 7.25 . It should be noted that the transmural heterogeneity in the canine left ventricle is exaggerated in the traditional wedge model, compared with the intact canine heart (Voss et al., 2009).

2. Langendorff Heart Preparation. The Langendorff perfused isolated heart as a model system to evaluate drug-induced delayed repolarization and proarrhythmia offers many of the advantages of the wedge preparation and eliminates concerns regarding artificially exaggerating surrogate markers as in the wedge preparation (Gintant, 2008). Isolated hearts are perfused at a constant pressure, the His bundle is sectioned to slow heart rate and a stimulating electrode sutured on each side of the distal His bundle. Recording electrodes are placed in the left ventricular subendocardium of the septum and on the left ventricular epicardium. An automated platform (SCREENIT) using methoxamine-pretreated female rabbit hearts subject to escalating drug concentrations has been developed and can assess pseudoECGs and action potentials from endocardial and epicardial surfaces (Hondeghem et al., 2001). This system was introduced initially to identify class III antiarrhythmic agents with use-dependence (i.e., greater action potential prolongation at faster rates) (Hondeghem, 1994) and also can be used to evaluate the potential for drugs to cause TdP or to evaluate antiarrhythmic drugs in models of congenital LQTS (Milberg et al., 2005). Several additional proarrhythmic repolarization disturbances have been identified or studied in this model, including triangulation of the action potential, reverseuse dependence, instability, and dispersion of action potential duration (APD), discussed further in section III.D (Hondeghem et al., 2001; Shah and Hondeghem, 2005). It should be noted that the isolated rabbit heart is less dependent upon $\mathrm{I}_{\mathrm{Ks}}$ for repolarization than other animal models. For example, chromanol 293B, a potent $\mathrm{I}_{\mathrm{Ks}}$ blocker (Sun et al., 2001) causes concentration-dependent TdP in isolated guinea pig hearts but not in isolated rabbit hearts (Cheng and Incardona, 2009). Therefore, the rabbit displays greater sensitivity to $\mathrm{I}_{\mathrm{Kr}}$ blockers than other species, which makes it especially useful as a screening tool.

In a blinded validation study, the SCREENIT system reliably identified 14 drugs with known effects on the QT interval, correctly identifying risk in eight potentially proarrhythmic drugs but not in 6 other drugs considered safe (Hondeghem and Hoffmann, 2003). In certain instances, the concentrations necessary to identify proarrhythmic risk greatly exceeded therapeutic concentrations. In another study, this system was used quantitatively to evaluate 55 compounds with varying levels of "torsadogenic" risk, demonstrating that a 30 fold margin between risk scores and the highest effective free plasma concentration would provide confidence that a new chemical entity should proceed through development, without incurring substantial risk of eliminating potentially beneficial drugs (Lawrence et al., 2006). A study comparing 82 compounds and their degree of $\mathrm{I}_{\mathrm{Kr}}$ block in cellular models, results from SCREENIT, and actual QT prolongation in nonrodent telemetry studies concluded that data from the isolated heart model would reduce the risk of discontinuing development of drugs that block $\mathrm{I}_{\mathrm{Kr}}$ but would not result in QT prolongation clinically (Dumotier et al., 2008).

\section{Whole Animal Models}

1. The Methoxamine-Sensitized Rabbit Model. The history behind the development of the anesthetized methoxamine-sensitized rabbit as a model for diLQTS is interesting. In the 1990s, the new $\mathrm{I}_{\mathrm{Kr}}$ blocker almokalant was noted to bind to melanin-pigmented structures in rats (Abrahamsson et al., 1994). Because of concerns about eye toxicity, the drug was given to conscious pigmented rabbits to determine whether the binding affinity was reversible or irreversible (Abrahamsson et al., 1994). The majority of animals died suddenly with plasma concentrations that were anticipated to be in the therapeutic range, and subsequent ECG recording showed TdP degenerating to ventricular fibrillation. Further studies in anesthetized rabbits resulted in much lower sensitivity to $\mathrm{I}_{\mathrm{Kr}}$ blockers; few animals experienced TdP and only at much higher doses than their unanesthetized counterparts. When pretreated with the $\alpha$-adrenoceptor blocker prazosin, animals were resistant to TdP with almokalant (Carlsson et al., 1990), and the selective $\alpha$-adrenoceptor agonist methoxamine is now used to sensitize anesthetized rabbits to $\mathrm{TdP}$ with $\mathrm{I}_{\mathrm{Kr}}$ blockers. It is still unclear exactly why either the conscious state or $\alpha$-adrenoceptor stimulation sensitizes the rabbit to $\mathrm{TdP}$, and this effect is not noted in cats or guinea pigs (Carlsson et al., 1993; Carlsson, 2008).

Early work using the methoxamine-sensitized rabbit model of TdP primarily studied potential novel class III antiarrhythmic drugs. Most of these agents were found to be highly proarrhythmic in the model, demonstrating that the model has a very high sensitivity in this setting. However, because the model relies heavily on the sensitizing effect of $\alpha$-adrenoceptor sensitization, the proarrhythmic potential of $\mathrm{I}_{\mathrm{Kr}}$ blockers with $\alpha$-adrenoceptor blocking properties may be underestimated. As an example, quinidine resulted in significant QT prolongation but no TdP using this model, despite the known clinical risk for TdP (Farkas et al., 2002). The $\alpha$-adrenoceptor blocking activity of quinidine, as well as cisapride and some quinolone antibiotics, probably result in the lack of specificity of the model for these drugs (Nattel et al., 2008).

A poor correlation between degree of QT interval prolongation and risk for TdP has been noted in this model. 
Neither the baseline QT interval nor the maximal QT response to the potent $\mathrm{I}_{\mathrm{Kr}}$ blocker dofetilide differed between rabbits susceptible to $\mathrm{TdP}$ and those that did not develop TdP (Carlsson, 2008). There have been few reports of alternative proarrhythmia markers in the rabbit model. An increase in QT beat-to-beat variability was noted before development of TdP in one study (Lengyel et al., 2007), but this has not been noted in other studies (Carlsson, 2008). The peak to the end of the QT interval has been noted to increase with dofetilide in methoxamine-sensitized rabbits but did not correlate with TdP (Carlsson, 2008) and did not prolong with dofetilide in phenylephrine-sensitized rabbits (Vincze et al., 2008). These measurements were performed in a single ECG lead (lead II) and are more reflective of global, not transmural dispersion of repolarization.

2. The Complete Atrioventricular Block Dog Model. The complete atrioventricular block (CAVB) dog model has been in existence for a century, but only in the last few decades has it been used as a model for proarrhythmic screening of drugs (Oros et al., 2008). After producing AV block, now most commonly performed with radiofrequency catheter ablation of the AV node, ventricular remodeling (contractile, structural, and electrical) occurs relatively rapidly. The ventricles increase in contractility, and develop hypertrophy, whereas current density of $\mathrm{I}_{\mathrm{Kr}}$ and $\mathrm{I}_{\mathrm{Ks}}$ are reduced, more prominently in the right ventricle. Increased calcium loading of the sarcoplasmic reticulum as a result of enhanced $\mathrm{Na}^{+} / \mathrm{Ca}^{2+}$ exchanger activity has also been noted (Sipido et al., 2000). This electrical remodeling process occurs by 2 weeks and remains relatively constant thereafter. In the conscious, drug-free state, these dogs undergoing long-term CAVB have a sudden death rate of approximately $10 \%$, with polymorphic ventricular tachycardia recorded by ECG surveillance in some instances (van Opstal et al., 2001). Anesthetic agents, possibly by blocking repolarizing currents (Stadnicka et al., 2000), make the animals more susceptible to drug challenge with QT-prolonging antiarrhythmics, resulting in TdP in roughly $70 \%$ of CAVB dogs. It is noteworthy that the development of $\mathrm{TdP}$ or lack of inducibility is highly reproducible in this model (Vos et al., 1995); thus, individual dogs can be categorized as drug-susceptible or drug-resistant.

Similar to the rabbit model above, the degree of prolongation of the surface QT interval or monophasic action potential by drug is a poor correlate to TdP; QTc and change in monophasic action potential are unable to discriminate between drug-susceptible and drug-resistant dogs (Thomsen et al., 2007). The beat-to-beat variability of repolarization (BVR), however, seems to be a much more specific marker. By comparing the duration of repolarization of one beat with the previous beat, an index of this beat-to-beat variability, quantified and calculated as follows: short-term variability $=\sum \mid D_{\mathrm{n}+1}-$ $D_{\mathrm{n}} \mid / 30(2)^{0.5}$, where $D$ is duration of repolarization and $\mathrm{n}$ is beat 1 to 30 . BVR is increased in the CAVB dog and increases further before developing TdP with drug only in those who are susceptible. Furthermore, interventions that reduced TdP in his model (serum potassium, pacing, and a potassium channel opener) all reduced BVR but not QT interval. Drugs and/or drug doses that do not result in TdP do not prolong BVR despite QT/QTc prolongation (Thomsen et al., 2006). The anesthetized CAVB dog displays reduced repolarization reserve and seems to provide greater specificity for discriminating between drugs that increase risk for $\mathrm{TdP}$ and those that do not, despite prolongation of the QT interval.

Although each of the various model systems discussed above has specific advantages and limitations, there are some generalizations that hold true. A major advantage of the simpler systems is relative ease and the ability to screen a large number of compounds at lower expense, potentially leading to automated, high-throughput processes. These are typically more useful early in drug development, when compounds that might pose risk (although not proven) can be abandoned. The systems of higher complexity are more time-consuming and expensive yet may provide a more thorough risk assessment as well as other more reliable indicators of risk than simple QT prolongation. These are more useful in assessing true (rather than potential) risk in compounds already released or near the end of the development process.

\section{Triangulation, Reverse Use-Dependence, Instability, Dispersion}

Several proarrhythmic repolarization disturbances have been identified or studied in the isolated heart model, including triangulation of the action potential, reverse-use dependence, instability, and dispersion of APD (Shah and Hondeghem, 2005). Triangulation is defined as prolongation of the interval from 30\% repolarization to $90 \%$ repolarization and can result from reduced outward current or increased inward current. Triangulation is thought to be proarrhythmic by increasing the time spent in the calcium and sodium window currents, augments depolarizing sodium/calcium exchange currents, and reduces outward current at the end of repolarization. Triangulation is expected to result in a widening and flattening of the T-wave on surface ECG, ultimately leading to notched T-waves. Reverse use-dependence is a property of most class III antiarrhythmic agents, which results in greater APD prolongation at slow heart rates, and is intrinsically proarrhythmic. Instability is another term for beat-to-beat variability of repolarization, as discussed below, and has a macroscopic counterpart in T-wave alternans. Dispersion of repolarization across macroscopic regions of the heart (including transmural, apex to base, septum to free wall, right to left ventricle, etc.) is observed normally, but when excessive, or when occurring microscopically, promotes EADs and TdP, as discussed above.

\section{Relating Risk Factors to Mechanisms}

The initial case series of diLQTS noted hypokalemia and AV block or other bradyarrhythmias as risk factors 
for TdP. During the 1970s and 1980s, the number of case reports and series of patients with diLQTS rose, increasing description of further risk factors. These are listed in Table 4, and the mechanisms whereby they increase TdP risk are discussed below. It is noteworthy that hypokalemia or female sex also increases risk of arrhythmias in the congenital syndrome. This clinical overlap between the congenital syndrome and the severe adverse drug effect, as well as the apparently "unpredictable" nature of diLQTS, forms the basis of ongoing studies to delineate pharmacogenetic and pharmacogenomic contributors to risk.

Some risk factors are drug-specific (e.g., pharmacokinetic factors such as cytochrome $\mathrm{P} 450$ variants that decrease drug clearance, elevate plasma drug concentrations, and thereby increase risk of toxicity) whereas others (pharmacodynamic factors) seem more related to myocardial sensitivity across drugs. Studies of the congenital syndrome have had important implications for understanding the latter. One important finding was variable penetrance in the congenital syndrome (Priori et al., 1999); that is, there is variability in the extent to which mutation carriers display long QT intervals, syncope, and sudden death. Thus, one pharmacogenetic hypothesis is that persons displaying diLQTS represent a "forme fruste" of the congenital form of the syndrome. As discussed in further detail in section VI.B, a minority of subjects with diLQTS do in fact harbor rare nonsynonymous variants (mutations) in cLQTS disease genes and can thus be labeled as having the congenital syndrome (Donger et al., 1997; Schulze-Bahr et al., 1997; Napolitano et al., 2000; Sesti et al., 2000; Yang et al., 2002; Paulussen et al., 2004; Nishio et al., 2009). More generally, the identification of multiple ion currents that accomplish normal repolarization has raised the possibility that variability in the extent to which drug challenge prolongs QT interval reflects variability in these (possibly redundant) mechanisms; this is the concept of repolarization reserve discussed above (Roden, 1998).

The heart rate is an important variable affecting the QT interval. As the heart rate increases QT shortens, comparison of QT intervals at different heart rates must take this into account; this is accomplished by a ratecorrection (QTc) using correction formulae; the most common are as follows:

Bazett (1920): QTc $=$ QT/RR interval ${ }^{1 / 2}$

Fridericia (1920)): QTc $=$ QT/RR interval ${ }^{1 / 3}$

Framingham-Sagie (Sagie et al., 1992): QTc $=$ QT + 154 ( 1 - 60/heart rate)

Hodges (Luo et al., 2004): $\mathrm{QTc}=\mathrm{QT}+1.75$ (heart rate -60 )

Nomogram-Karjalainen (Karjalainen et al., 1994): $\mathrm{QTc}=\mathrm{QT}+$ Nomogram correction factor.

Each approach has its deficiencies; no single "correct" method for deriving the QT value has been established (Malik et al., 2002). Drugs may independently affect the QT interval and the heart rate, and the successful treat- 
ment of a disease (such as infection or psychosis) may itself change the heart rate, further complicating the assessment of the QT interval at varying heart rates.

\section{A. Female Sex}

A summary of published data led Makkar et al. (1993) to identify a $2: 1$ to $3: 1$ female predominance in diLQTS. An increased risk of cardiac events is also observed in women with some forms of the cLQTS but only after childhood (Zareba et al., 2003). These clinical observations, coupled with the finding that the QT shortens after puberty in men but not women (Rautaharju et al., 1992), suggest that sex hormones modulate repolarization. Testosterone, by increasing $\mathrm{I}_{\mathrm{Kr}}$ and $\mathrm{I}_{\mathrm{Kur}}$, shortens QTc and has been implicated as the major factor lowering risk of TdP in men (Arya, 2005). Recent work in a prepubertal rabbit model reveals that an $\mathrm{I}_{\mathrm{Kr}}$ blocker results in greater APD prolongation in men compared with women and caused EADs and ventricular tachycardia only in men (Liu et al., 2005b). This finding may explain the higher risk of events in male children with cLQTS but cannot be attributed to gonadal steroid effects.

Although sex hormones play a role in QTc differences between men and women, they explain only part of the observed differences. Androgens are protective against drug-induced prolongation of repolarization, whereas estrogens seem to be proarrhythmic. Although sex differences in the density of ionic channels do exist (Liu et al., 1998), they seem to only partially explain women's increased risk of diLQTS and TdP. This suggests that heretofore unrecognized mechanisms, such as modulation of the pharmacokinetics of $\mathrm{I}_{\mathrm{Kr}}$ blockers (discussed further below), may be important in determining sexrelated differences in risk of developing drug-induced prolongation of the QT interval (Hreiche et al., 2008).

\section{B. Bradycardia}

Bradycardia, as seen with CAVB, is a commonly observed risk factor for diLQTS and TdP. Although this association was first described over 40 years ago (Dessertenne, 1966), remarkably little is known about the ECG predictors of this potentially lethal complication of bradyarrhythmias (Strasberg et al., 1986; Kurita et al., 1992). Indeed, the "short-long-short" series of cycles before TdP discussed below is so characteristic of diLQTS that lack of a "pause" before onset calls into question the diagnosis. Bradycardia is largely caused by a slow sinus rhythm, hypothermia, or hypothyroidism, all of which can physiologically prolong ventricular repolarization and lead to a higher risk of TdP. However, a pause provoked by extrasystoles may be more important than bradycardia per se at the initiation of TdP (Roden and Anderson, 2000).

1. The "Short-Long-Short" Series of Cycling Changes before the Initiation of an Event. The association between this stereotypical series of cycle-length changes and the initiation of TdP is probably a clue to underlying mechanisms (Kay et al., 1983; Roden et al., 1986) (Fig. 3 ). These cycle-length changes have two major effects that could, in theory, promote TdP: 1) there is striking deformity of the pause after the QT interval, often with the development of a large U-wave (Viskin et al., 2004; Topilski et al., 2007; Kirchhof et al., 2009), suggesting a role for afterdepolarizations discussed in section II.C, and 2) the short-long sequence maximizes the heterogeneity of repolarization times of the last sinus beat, thereby increasing the likelihood of reentrant excitation (Roden and Anderson, 2000).

\section{Hypokalemia and Hypomagnesemia}

Lowering of extracellular potassium decreases $\mathrm{I}_{\mathrm{Kr}}$, an effect that is likely to contribute to QT interval prolongation in hypokalemic patients (Yang et al., 1997). However, this effect on $\mathrm{I}_{\mathrm{Kr}}$ is unexpected because simple electrochemical considerations predict an increase in outward potassium current with lowering of extracellular potassium. Two possible mechanisms have been advanced to explain this paradoxical behavior: one is that sodium and potassium ions compete for access to extracellular binding sites on the channel, and sodium is a potent blocker of the current (Numaguchi et al., 2000). Consequently, when extracellular potassium is lowered, the inhibitory effect of sodium on $\mathrm{I}_{\mathrm{Kr}}$ becomes more apparent. The second explanation involves the very rapid inactivation that $\mathrm{I}_{\mathrm{Kr}}$ undergoes after opening during depolarizing pulses (Yang et al., 1997). Lowering of extracellular potassium enhances this fast inactivation, so with hypokalemia, more channels are in the inactivated state and fewer in the open configuration during depolarizing pulses. This very rapid inactivation also explains why KCNH2 channel, which generates $\mathrm{I}_{\mathrm{Kr}}$, plays such a key role in repolarization (Fig. 4).

Another twist on hypokalemia as a risk factor for TdP has been the observation that drug blockade is actually enhanced at low levels of extracellular potassium (Yang and Roden, 1996; Wang et al., 1997). Thus, hypokalemia enhances TdP risk through at least two mechanisms: 1) decrease in the repolarizing current itself and 2) potentiation of drug blockade of residual current.

Hypomagnesemia increases TdP risk, possibly by modulating the L-type calcium channel function that contributes to EADs. Recognition of hypomagnesemia as a contributor to acquired QT prolongation and TdP (Kay et al., 1983; Roden, 1989) led to empiric testing of intravenous magnesium as a therapy (Tzivoni et al., 1988). Although no randomized prospective trial has been conducted, intravenous magnesium has become a first-line therapy for TdP due to diLQTS.

\section{Atrial Fibrillation}

The most common arrhythmia requiring drug therapy is $\mathrm{AF}$, which affects 2 to 5 million Americans and continues to be a major cause of morbidity, such as heart failure and stroke (Wattigney et al., 2002). Recent ran- 
domized trials in minimally symptomatic patients have argued against vigorous attempts to maintain sinus rhythm (Wyse et al., 2002). However, in such trials, patients maintaining sinus rhythm have improved outcomes, and many patients are highly symptomatic with AF. Thus, maintaining sinus rhythm with antiarrhythmic drugs remains an important goal for many patients with $\mathrm{AF}$. However, many antiarrhythmic drugs block $\mathrm{I}_{\mathrm{Kr}}$ as a major mechanism of action, and marked QT prolongation and $\mathrm{TdP}$ are the major class toxicities.

Multiple lines of clinical evidence suggest that AF itself protects against $\mathrm{TdP}$ and that after conversion, risk is increased. One common clinical observation is that TdP often [but not always (Stambler et al., 1996)] occurs in patients with $\mathrm{AF}$ after conversion to sinus rhythm (Levy, 1922; Motté et al., 1970) (Fig. 1). This may reflect the decrease in heart rate that often accompanies such conversion, but studies conducted in the late 1990s indicate that the mechanisms must be more complicated. In a small study, we examined the extent of QT prolongation by intravenous dofetilide during $\mathrm{AF}$ and shortly after conversion to sinus rhythm. Despite the fact that dofetilide did not change heart rate, the extent of QT prolongation was much greater in sinus rhythm than in AF (Choy et al., 1999). Indeed, more recently, we have gone on to show that QT-RR slopes are extraordinarily flat during AF (i.e., even with long pauses, the QT interval does not prolong) and steepen very sharply, to greater than normal values, shortly after conversion to sinus rhythm (Darbar et al., 2007). We therefore infer that $\mathrm{AF}$ itself may exert a heretofore poorly understood influence on the QT interval both during arrhythmia and shortly after its conversion to normal rhythm.

$\mathrm{AF}$ is associated with significant atrial remodeling that includes alterations in L-type calcium current, inward rectifier current, transient outward current, and ultrarapid delayed rectifier current (among other changes) (Nattel, 2001). The magnitude of these changes is sufficient to alter responses to antiarrhythmic drugs. However, molecular changes in the left ventricle secondary to AF are less well established. Nonetheless, there are echocardiographic data that links $\mathrm{AF}$, atrial remodeling, reverse remodeling, and changes in left ventricular systolic function (Reant et al., 2005).

Although the precise mechanism by which AF reduces susceptibility to TdP is unknown, AF-associated electrophysiological and cellular remodeling may be associated with preservation of TDR that correlates with reduced susceptibility to the development of TdP among patients with diLQTS. In addition, a recent study that modeled LQTS by infusing veratridine into Langendorff preparations of rabbit hearts as described in section IV.B.2, was able to demonstrate that the risk of developing TdP could be significantly decreased through preventing prolongation in TDR by verapamil administration (Milberg et al., 2005).

\section{E. Role of Variable Drug Concentrations in Torsades de Pointes Risk}

Initial reports with quinidine noted that the adverse effect often occurred within $24 \mathrm{~h}$ of starting the drug, at a time when excessive accumulation of drug (or potentially active metabolites) would not be expected. Indeed, with routine plasma concentration monitoring came the frequent observations of "subtherapeutic" quinidine concentrations in patients developing TdP (Levy, 1922; Jenzer and Hagemeijer, 1976; Roden et al., 1986). Studies as early as the 1940s (Brodie and Udenfriend, 1943; Brodie et al., 1951) identified multiple quinidine metabolites, raising the possibility that variability in response to the drug might reflect variable activity or accumulation of metabolite(s). However, subsequent studies established that the multiple metabolites demonstrate less in vitro electrophysiologic activity than the parent drug (Thompson et al., 1987) and that plasma concentrations at the time of TdP were generally lower for the metabolite compared with the parent drug (Thompson et al., 1988). The lack of a relationship between plasma quinidine concentrations and TdP risk probably reflects the drug's inhibition of multiple ion currents with a range of potencies: block of $\mathrm{I}_{\mathrm{Kr}}$ at low concentrations (Yang and Roden, 1996) to prolong action potentials, block of other potassium currents at higher concentrations to prolong action potentials (Hiraoka et al., 1986; Imaizumi and Giles, 1987), and block of sodium current (in a frequency-dependent fashion) to shorten action potentials (Johnson and McKinnon, 1957; Roden et al., 1987).

By contrast, TdP developing during therapy with most other antiarrhythmic agents (sotalol, dofetilide) and noncardiovascular therapies (thioridazine, methadone) seems to be dose- or concentration-related (Reiffel and Appel, 2001; Krantz et al., 2002). Thus, conditions leading to accumulation of QT-prolonging agents in plasma are, in general, risk factors for TdP. Sotalol and dofetilide undergo renal excretion and therefore require dose reductions in patients with reduced renal function to avoid TdP (Anderson and Prystowsky, 1999; Reiffel and Appel, 2001). This concept extends to drug metabolism: thioridazine is a CYP2D6 substrate, and some data suggest that the drug accumulates in plasma in poor metabolizers with more marked QT prolongation (Llerena et al., 2000). Likewise, the QT prolonging $S$-enantiomer of methadone is eliminated by CYP2B6-mediated metabolism, and persons with reduction-of-function alleles in this gene may therefore be at increased risk for methadone-induced TdP (Eap et al., 2007).

\section{F. Impact of QT Prolongation on Drug Development}

It was, in fact, an interaction between drug metabolism and elimination of a drug with QT prolonging potential that began to attract regulatory and subsequently drug development activity. A case report in 1989 described a young woman who presented with typical 
drug-induced TdP during therapy with the antihistamine terfenadine and ketoconazole, which she had borrowed from a friend to treat a vaginal infection (Monahan et al., 1990). This sentinel event led to a review of cases of terfenadine-associated diLQTS and an understanding of underlying mechanisms. Terfenadine is a potent $\mathrm{I}_{\mathrm{Kr}}$-blocking drug but usually undergoes nearly complete presystemic metabolism to a noncardioactive metabolite, fexofenadine, which retains the antihistamine activity (Woosley et al., 1993). Cases of terfenadine-induced diLQTS were usually associated with overdose (Davies et al., 1989) or inhibition of CYP3A4, the enzyme responsible for terfenadine biotransformation in the gut and liver to accomplish presystemic elimination. The identification of a very small number of cases of diLQTS, however, markedly upset the risk-benefit calculations for the drug: the publically promulgated regulatory view was that the drug was prescribed for a nonlethal indication (allergies) and that even a small risk of a fatal adverse drug reaction was therefore unacceptable. Attempts by regulatory authorities (Burkhart et al., 1997) to make physicians and the public aware of the dangers of drug interactions with terfenadine, including black box warnings and educational programs, were ultimately unsuccessful (Cavuto et al., 1996; Thompson and Oster, 1996; Woosley, 2000) and when fexofenadine was approved for therapy, terfenadine was withdrawn.

In the same period, a second antihistamine, astemizole, was also associated with diLQTS, especially with drug interactions and overdose, although in this case the major metabolite is also an $\mathrm{I}_{\mathrm{Kr}}$ blocker (Snook et al., 1988; Vorperian et al., 1996; Tsai et al., 1997; Zhou et al., 1999). A third drug, cisapride, a gastric promotility agent, was also relabeled and ultimately withdrawn for very similar findings: rare cases of TdP, especially with drug interactions and overdose (Piquette, 1999; Walker et al., 1999). This is not a "class effect" because other nonsedating antihistamines and gastric promotility agents lack the potential to produce diLQTS.

In controlled clinical trials, coadministration of ketoconazole or erythromycin with terfenadine produced marked (>80-100 ms) increases in QT interval and U waves (Honig et al., 1992, 1993). A small clinical trial in the mid-1990s established that even therapeutic doses of terfenadine alone produced small, albeit measurable, increases in rate-corrected QT interval, on the order of 6 $\mathrm{ms}$ in a group of healthy volunteers (Pratt et al., 1996). The extent of QT prolongation was increased if the terfenadine dose was increased and was greater in patients with underlying heart disease compared with healthy volunteers. As a result of this trial, and the events surrounding withdrawal of terfenadine, astemizole, and cisapride, it is now routine to assess the extent to which any new compound in development prolongs the QT interval. This is accomplished by a "thorough QT" study. The most common design assesses the QT intervals during a four-arm trial: 1) steady state of usual drug dos- ages; 2) steady state of higher dosages (or during metabolic inhibition); 3) a drug known to produce a small QT interval increase, most often the antibiotic moxifloxacin, as a positive control; and 4) placebo (Shah, 2005a; Bloomfield et al., 2008; Malik et al., 2008; Sethuraman and Sun, 2009). Because QT is dependent on rate, QT values are rate-corrected, generally using the Fridericia formula. The analysis compares QT changes at each time point with drug compared with those with placebo, and the results are usually presented as the percentage of subjects with delta QTc values (at maximum drug effect) $>30$ and $>60 \mathrm{~ms}$, and the percentage with QTc values $>500 \mathrm{~ms}$ at any time point. The positive control is included to ensure that the study conduct and measurement protocols are consistent with other trials; moxifloxacin generally produces a 7- to $10-\mathrm{ms}$ increase in QTc with no changes $>30 \mathrm{~ms}$. Drug candidates that produce clear QT prolongation in this paradigm will likely progress to market only if the indication is a pressing and compelling one for which other therapies are unavailable.

A high-potency $\mathrm{I}_{\mathrm{Kr}}$-blocking agent is unlikely to progress during development because of the concern that, like terfenadine, it may generate cases of $\mathrm{TdP}$. Thus, assessment of $\mathrm{KCNH} 2 / \mathrm{I}_{\mathrm{Kr}}$-blocking activity is generally accomplished before first-in-man drug studies. By contrast, the thorough QT study generally has to wait until a dose that would be used in humans for the anticipated indication is identified. However, as discussed above, even terfenadine produced diLQTS in a very small number of patients. Thus, the current algorithms are designed to identify drugs that might produce diLQTS in a small proportion of exposed patients.

The extent to which such rigorous testing for an adverse drug effect has resulted in abandonment of potentially beneficial compounds has been the subject of extensive debate (Shah, 2005a,b; Pollard et al., 2008). As discussed above, studies in animal models have suggested that TdP is not as well correlated with prolongation of the QT interval as it is with temporal instability of the action potential (Hondeghem and Hoffmann, 2003; Hondeghem, 2006; Thomsen et al., 2006), further throwing into question the utility of current screening algorithms. It is noteworthy that non- $\mathrm{I}_{\mathrm{Kr}}$-blocking mechanisms for QT prolongation discussed above are not generally sought in current preclinical screening algorithms.

There seems little doubt that a better understanding of underlying mechanisms has resulted in an improved ability to identify drugs with QT prolonging potential, to the point that it is possible to identify even drugs that carry very tiny risks, seen as a handful of cases of TdP in very large numbers of exposed patients. Indeed, there have been case reports of TdP with moxifloxacin (Altin et al., 2007; Dale et al., 2007; Sherazi et al., 2008). Thus, it is entirely possible that potentially useful drugs have therefore been abandoned based on the possibility of a 
severe adverse drug event occurring in literally one in a million exposed subjects, emphasizing the risk-benefit calculus inherent in prescribing any drug, and the unrealistic goal of guaranteeing no risk with drug therapy. The association between some drugs and diLQTS is incontrovertible: quinidine, sotalol, dofetilide, thioridazine, and methadone. For others, occasional case reports have been published, but the totality of the database suggests that risk is either absent or very low. Thus, for example, although there have been case reports of fluoxetine-associated TdP (Appleby et al., 1995; Lherm et al., 2000) and it is a weak $\mathrm{I}_{\mathrm{Kr}}$ blocker (Buff et al., 1991; Thomas et al., 2002), the drug has been very widely used and yet the number of cases is vanishingly small. Lists of culprit drugs and a rough estimate of the risks with which each is associated are maintained at the web site http://www.torsades.org.

\section{Genetics and Genomics of Drug-Induced Long QT Syndrome}

Advances in genetics and genome science have resulted in identification of both rare alleles (generally unrecognized cLQTS mutations) as well as common variants, most often in ion channel genes, that seem to increase risk for diLQTS as discussed in sections II.B and II.C. Brief reports suggest that patients displaying diLQTS in response to treatment with one QT prolonging antiarrhythmic would also develop TdP in response to exposure to other potential culprits (Lazzara, 1993). Whether this represents acquired sensitivity to the drugs (e.g., due to heart disease) or underlying genetic susceptibility remains to be determined.

\section{A. Support for a Genetic Predisposition}

Although diLQTS is unpredictable in a given patient or population, similarities to the cLQTS insinuate a genetic component to risk. Consider the spectrum of responses in a cohort of similar patients treated with a QT-prolonging drug such as sotalol for AF: a minority (group A) develops severe QT prolongation and TdP; some (group B) develop QT prolongation, resulting in discontinuation of the drug; and others (group C) safely tolerate long-term therapy. Although the clinical risk factors discussed above can be identified in many patients with diLQTS (group A), these are also present in many who safely tolerate QT-prolonging drugs (group C). Thus, despite similar substrates and environmental risk factors, these subsets of patients respond very differently to QT-prolonging drugs. If these different responses occur because the patients in group A are genetically predisposed to diLQTS, then the relatives of patients in group $\mathrm{A}$ and group $\mathrm{C}$ should also respond differently to QT-prolonging drugs. To test for a genetic component to risk for diLQTS, we administered quinidine to first-degree relatives of patients with diLQTS and to first-degree relatives of patients who safely tol- erated long-term therapy with QT-prolonging drugs (Kannankeril et al., 2005). Although the QT and QTc intervals were similarly prolonged, the peak-to-end of the T-wave increased significantly only in the relatives of patients with diLQTS. This study demonstrated greater prolongation of terminal repolarization in relatives of patients with diLQTS, suggesting a genetic predisposition to drug-induced QT prolongation.

\section{B. Rare Mutations}

As discussed above, with the identification of rare mutations in ion channel genes underlying cLQTS and the investigation of large pedigrees, the phenomenon of incomplete penetrance has become apparent (Priori et al., 1999). In a given family, some persons with a LQTS mutation have unambiguously long QT intervals, whereas others with the same mutation have normal QT intervals at baseline. In some cases, these latter people, often referred to as "latent," "silent," or "subclinical" LQTS, experience TdP only after therapy with a QTprolonging drug. Indeed, when cLQTS disease genes have been screened, mutations are identified in $\sim 10 \%$ of subjects with diLQTS (Yang et al., 2002; Paulussen et al., 2004).

\section{Common Variants}

More common polymorphisms in ion channel and other genes have been described that have minor functional effects at baseline, yet when compounded with a QT-prolonging drug may increase risk for TdP. In one study of patients treated with dofetilide, the common SCN5A polymorphism H558R was over-represented in those with TdP (37.5\%) compared with those without TdP (14.4\%) (Mank-Seymour et al., 2006). Other common ion channel polymorphisms that have been implicated in small studies of diLQTS include KCNH2 R1047L, KCNE1 D85N, and KCNE2 T8A and Q9E (Fitzgerald and Ackerman, 2005). As discussed above, common variants in drug metabolism pathways may also predispose to diLQTS in a drug-specific fashion: CYP2D6 variants/thioridazine and CYP2B6/methadone are two examples discussed above.

The technique of genome-wide association has been applied to study identify loci at which common variants modulate variability in normal QT interval across populations, and multiple loci have been identified (Arking et al., 2006) (Newton-Cheh et al., 2009; Pfeufer et al., 2009). The largest signal in these studies is in a chromosome 1 locus, and the nearest gene, NOS1AP, has subsequently been implicated as a modulator of action potential duration in guinea pig myocytes (Chang et al., 2008). The genome-wide association scan approach to normal QT has also implicated common variants in cLQTS disease genes (SCN5A, KCNJ2, KCNQ1, and $K C N H 2$ ), other genes thought to play a role in cardiac electrophysiology (e.g., phospholamban, a regulator of intracellular calcium), and entirely new loci. One of 
these includes GINS3, which has also been implicated as a modulator of heart-rate response to dofetilide challenge in zebrafish (Milan et al., 2009).

The extent to which these variants modulate drug response in human subjects is now an area of active investigation. In one study, cardiovascular deaths during treatment with dihydropyridine calcium-channel blockers were associated with NOS1AP variants (Becker et al., 2009). NOS1AP and other candidate genes have also been studied as predictors of the more general and widespread problem of sudden cardiac death (SCD). In large community cohorts [Atherosclerosis Risk in Communities (ARIC), Cardiovascular Health Study (CHS)], NOS1AP variants were associated with up to 1.3 -fold increased risk (per allele) (Kao et al., 2009). This finding reinforces reports (Schwartz and Wolf, 1978; de Bruyne et al., 1999) that risk of SCD increases with longer QT intervals (regardless of drug therapy). Most recently, a survey of SCD victims in Portland, OR, not only confirmed the link to baseline QT but also implicated QTprolonging drug therapy as a contributor more generally (Chugh et al., 2009). In another report, variants in SCN5A were suggested to be predictors of SCD in women (Albert et al., 2008).

Platforms to interrogate hundreds of polymorphisms in selected candidate genes or hundreds of thousands across the genome are now being deployed to analyze the problem of diLQTS. One recent report analyzed 1536 common single-nucleotide polymorphisms in 19 candidate genes, including NOS1AP, cLQTS disease genes, and other genes encoding cardiac ion channels (Kääb et al., 2008). Patients with drug-induced torsades de pointes $(n=326)$ were compared with patients tolerating QT-prolonging drugs and to population controls. The initial findings suggest that single-nucleotide polymorphisms in genes that encode proteins responsible for $\mathrm{I}_{\mathrm{Ks}}$ are markers of risk, consistent with the reduced repolarization reserve concept discussed in section III.D. The same group has also performed a genome-wide analysis in this set and has reported that this approach identifies multiple loci associated with risk; interestingly, the highest risk loci do not include ion channel genes, suggesting that other as-yet-unidentified pathways contribute to risk (Kääb et al., 2009).

\section{Conclusions and Perspectives}

Study of the drug-associated form of the long QT syndrome has progressed from labeling the event as "idiosyncratic" and hence unpredictable to an emerging complex molecular and genetic framework that indicates patients at high risk can be identified. Several key features of the studies outlined here also apply to other serious adverse drug events (Wilke et al., 2007), so studies in the field may advance our understanding of how to approach this problem more generally. These include
1) a set of drugs with which risk seems especially high, facilitating ascertainment of both case subjects and drug-exposed control subjects; 2) a common pathway to the adverse drug event, allowing cases associated with diverse drugs to be analyzed together; 3 ) an endpoint (in this case the QT interval) that can act as an imperfect surrogate for risk, allowing mechanistic studies to go forward; and 4) a low background rate (few other conditions cause torsades de pointes with marked QT interval prolongation); and 5) an argument that genetic background may play a role, and series of candidate genes to be studied.

A focus on drug-induced QT interval prolongation has advanced our understanding of normal physiology and of mechanisms underlying variable drug responses. These concepts have now been incorporated into the drug development process. As the discussion above makes clear, this has created a tension between those who feel excellent candidate drug molecules are being withheld from the development process because of an indefinable and possibly vanishingly small risk, and those who feel that current and new screening technologies can protect the public from the catastrophic scenario of marketing a drug with a moderate risk of unexpected and serious toxicity (Roden, 2005). It is conceivable that with advances in personal genomics will come the ability to predict with high accuracy risk for adverse drug effects. Meanwhile, understanding the mechanisms underlying drug actions, especially toxicities such as the diLQTS, remains the best way forward to choosing among available therapies for individual patients and to developing new safe and effective treatments.

Acknowledgments. This work was supported in part by the National Institutes of Health National Heart, Lung, and Blood Institute [Grants HL49989, HL65962, HL085690, HL092217].

\section{REFERENCES}

Abbott GW, Sesti F, Splawski I, Buck ME, Lehmann MH, Timothy KW, Keating MT, and Goldstein SA (1999) MiRP1 forms IKr potassium channels with HERG and is associated with cardiac arrhythmia. Cell 97:175-187.

Abrahamsson C, Palmer M, Ljung B, Duker G, Bäärnhielm C, Carlsson L, and Danielsson B (1994) Induction of rhythm abnormalities in the fetal rat heart. A tentative mechanism for the embryotoxic effect of the class III antiarrhythmic agent almokalant. Cardiovasc Res 28:337-344.

Aiba T, Shimizu W, Inagaki M, Noda T, Miyoshi S, Ding WG, Zankov DP, Toyoda F, Matsuura H, Horie M, et al. (2005) Cellular and ionic mechanism for drug-induced long QT syndrome and effectiveness of verapamil. J Am Coll Cardiol 45:300-307.

Albert CM, Nam EG, Rimm EB, Jin HW, Hajjar RJ, Hunter DJ, MacRae CA, and Ellinor PT (2008) Cardiac sodium channel gene variants and sudden cardiac death in women. Circulation 117:16-23.

Altin T, Ozcan O, Turhan S, Ongun Ozdemir A, Akyurek O, Karaoguz R, and Guldal M (2007) Torsade de pointes associated with moxifloxacin: a rare but potentially fatal adverse event. Can J Cardiol 23:907-908.

Anderson CL, Delisle BP, Anson BD, Kilby JA, Will ML, Tester DJ, Gong Q, Zhou Z Ackerman MJ, and January CT (2006) Most LQT2 mutations reduce Kv11.1 (hERG) current by a class 2 (trafficking-deficient) mechanism. Circulation 113: 365-373

Anderson JL and Prystowsky EN (1999) Sotalol: An important new antiarrhythmic. Am Heart J 137:388-409.

Antzelevitch C (2008) Drug-induced spatial dispersion of repolarization. Cardiol $J$ 15:100-121.

Antzelevitch C and Fish J (2001) Electrical heterogeneity within the ventricular wall. Basic Res Cardiol 96:517-527.

Antzelevitch C and Sicouri S (1994) Clinical relevance of cardiac arrhythmias generated by afterdepolarizations. Role of $\mathrm{M}$ cells in the generation of $\mathrm{U}$ waves, triggered activity and torsade de pointes. J Am Coll Cardiol 23:259-277.

Antzelevitch C, Sicouri S, Litovsky SH, Lukas A, Krishnan SC, Di Diego JM, Gintant GA, and Liu DW (1991) Heterogeneity within the ventricular wall. Electrophysi- 
ology and pharmacology of epicardial, endocardial, and M cells. Circ Res 69:14271449.

Appleby M, Mbewu A, and Clarke B (1995) Fluoxetine and ventricular torsade-is there a link? Int $J$ Cardiol 49:178-180.

Arking DE, Pfeufer A, Post W, Kao WH, Newton-Cheh C, Ikeda M, West K, Kashuk C, Akyol M, Perz S, et al. (2006) A common genetic variant in the NOS1 regulator NOS1AP modulates cardiac repolarization. Nat Genet 38:644-651.

Arya A (2005) Gender-related differences in ventricular repolarization: beyond gonadal steroids. J Cardiovasc Electrophysiol 16:525-527.

Bazett HC (1920) An analysis of the time relations of electrocardiograms. Heart 7:353.

Becker ML, Visser LE, Newton-Cheh C, Hofman A, Uitterlinden AG, Witteman JC, and Stricker BH (2009) A common NOS1AP genetic polymorphism is associated with increased cardiovascular mortality in users of dihydropyridine calcium channel blockers. Br J Clin Pharmacol 67:61-67.

Bloomfield DM, Kost JT, Ghosh K, Hreniuk D, Hickey LA, Guitierrez MJ, Gottesdiener K, and Wagner JA (2008) The effect of moxifloxacin on QTc and implications for the design of thorough QT studies. Clin Pharmacol Ther 84:475-480.

Bowlby MR, Peri R, Zhang H, and Dunlop J (2008) hERG (KCNH2 or Kv11.1) K channels: screening for cardiac arrhythmia risk. Curr Drug Metab 9:965-970.

Brodie BB, Baer JE, and Craig LC (1951) Metabolic products of the cinchona alkaloids in human urine. J Biol Chem 188:567-581.

Brodie BB and Udenfriend S (1943) Estimation of quinidine in human plasma, with note of estimation of quinidine. J Pharmacol Exp Ther 78:154.

Buff DD, Brenner R, Kirtane SS, and Gilboa R (1991) Dysrhythmia associated with fluoxetine treatment in an elderly patient with cardiac disease. J Clin Psychiatry 52:174-176.

Burashnikov A and Antzelevitch C (1998) Acceleration-induced action potential prolongation and early afterdepolarizations. J Cardiovasc Electrophysiol 9:934948.

Burkhart GA, Sevka MJ, Temple R, and Honig PK (1997) Temporal decline in filling prescriptions for terfenadine closely in time with those for either ketoconazole or erythromycin. Clin Pharmacol Ther 61:93-96.

Carlsson L (2008) The anaesthetised methoxamine-sensitised rabbit model of torsades de pointes. Pharmacol Ther 119:160-167.

Carlsson L, Abrahamsson C, Andersson B, Duker G, and Schiller-Linhardt G (1993) Proarrhythmic effects of the class III agent almokalant: importance of infusion rate, QT dispersion, and early afterdepolarisations. Cardiovasc Res 27:2186-2193.

Carlsson L, Almgren O, and Duker G (1990) QTU-prolongation and torsades de pointes induced by putative class III antiarrhythmic agents in the rabbit: etiology and interventions. J Cardiovasc Pharmacol 16:276-285.

Cavuto NJ, Woosley RL, and Sale M (1996) Pharmacies and prevention of potentially fatal drug interactions. JAMA 275:1086-1087.

Chang KC, Barth AS, Sasano T, Kizana E, Kashiwakura Y, Zhang Y, Foster DB, and Marbán E (2008) CAPON modulates cardiac repolarization via neuronal nitric oxide synthase signaling in the heart. Proc Natl Acad Sci USA 105:4477-4482.

Chen L, Marquardt ML, Tester DJ, Sampson KJ, Ackerman MJ, and Kass RS (2007) Mutation of an A-kinase-anchoring protein causes long-QT syndrome. Proc Natl Acad Sci USA 104:20990-20995

Cheng HC and Incardona J (2009) Models of torsades de pointes: effects of FPL64176, DPI201106, dofetilide, and chromanol 293B in isolated rabbit and guinea pig hearts. J Pharmacol Toxicol Methods 60:174-184.

Chézalviel-Guilbert F, Weissenburger J, Davy JM, Guhennec C, Poirier JM, and Cheymol G (1995) Proarrhythmic effects of a quinidine analog in dogs with chronic A-V block. Fundam Clin Pharmacol 9:240-247.

Chow MJ, Piergies AA, Bowsher DJ, Murphy JJ, Kushner W, Ruo TI, Asada A Talano JV, and Atkinson AJ Jr (1984) Torsade de pointes induced by Nacetylprocainamide. J Am Coll Cardiol 4:621-624.

Choy AM, Darbar D, Dell'Orto S, and Roden DM (1999) Exaggerated QT prolongation after cardioversion of atrial fibrillation. J Am Coll Cardiol 34:396-401.

Chugh SS, Reinier K, Singh T, Uy-Evanado A, Socoteanu C, Peters D, Mariani R, Gunson K, and Jui J (2009) Determinants of prolonged QT interval and their contribution to sudden death risk in coronary artery disease: the Oregon Sudden Unexpected Death Study. Circulation 119:663-670.

Cordes JS, Sun Z, Lloyd DB, Bradley JA, Opsahl AC, Tengowski MW, Chen X, and Zhou J (2005) Pentamidine reduces hERG expression to prolong the QT interval. Br J Pharmacol 145:15-23.

Curran ME, Splawski I, Timothy KW, Vincent GM, Green ED, and Keating MT (1995) A molecular basis for cardiac arrhythmia: HERG mutations cause long QT syndrome. Cell 80:795-803.

Dale KM, Lertsburapa K, Kluger J, and White CM (2007) Moxifloxacin and torsade de pointes. Ann Pharmacother 41:336-340.

Dangman KH and Hoffman BF (1981) In vivo and in vitro antiarrhythmic and arrhythmogenic effects of $N$-acetyl procainamide. J Pharmacol Exp Ther 217:851862.

Darbar D, Hardin B, Harris P, and Roden DM (2007) A rate-independent method of assessing QT-RR slope following conversion of atrial fibrillation. J Cardiovasc Electrophysiol 18:636-641.

Darbar D, Kimbrough J, Jawaid A, McCray R, Ritchie MD, and Roden DM (2008) Persistent atrial fibrillation is associated with reduced risk of torsades de pointes in patients with drug-induced long QT syndrome. J Am Coll Cardiol 51:836-842.

Davies AJ, Harindra V, McEwan A, and Ghose RR (1989) Cardiotoxic effect with convulsions in terfenadine overdose. BMJ 298:325.

de Bruyne MC, Hoes AW, Kors JA, Hofman A, van Bemmel JH, and Grobbee DE (1999) Prolonged QT interval predicts cardiac and all-cause mortality in the elderly. The Rotterdam Study. Eur Heart J 20:278-284.

Dessertenne F (1966) [Ventricular tachycardia with 2 variable opposing foci]. Arch Mal Coeur 59:263-272.

Donger C, Denjoy I, Berthet M, Neyroud N, Cruaud C, Bennaceur M, Chivoret G, Schwartz K, Coumel P, and Guicheney P (1997) KVLQT1 C-terminal missense mutation causes a forme fruste long-QT syndrome. Circulation 96:2778-2781.
Dorian P (2000) Mechanisms of action of class III agents and their clinical relevance. Europace 1:C6-C9.

Dumotier BM, Deurinck M, Yang Y, Traebert M, and Suter W (2008) Relevance of in vitro SCREENIT results for drug-induced QT interval prolongation in vivo: a database review and analysis. Pharmacol Ther 119:152-159.

Eap CB, Crettol S, Rougier JS, Schläpfer J, Sintra Grilo L, Déglon JJ, Besson J, Croquette-Krokar M, Carrupt PA, and Abriel H (2007) Stereoselective block of hERG channel by (S)-methadone and QT interval prolongation in CYP2B6 slow metabolizers. Clin Pharmacol Ther 81:719-728.

El-Sherif N, Caref EB, Chinushi M, and Restivo M (1999) Mechanism of arrhythmogenicity of the short-long cardiac sequence that precedes ventricular tachyarrhythmias in the long QT syndrome. J Am Coll Cardiol 33:1415-1423.

Farkas A, Leprán I, and Papp JG (2002) Proarrhythmic effects of intravenous quinidine, amiodarone, D-sotalol, and almokalant in the anesthetized rabbit model of torsade de pointes. J Cardiovasc Pharmacol 39:287-297.

Fenichel RR, Malik M, Antzelevitch C, Sanguinetti M, Roden DM, Priori SG, Ruskin JN, Lipicky RJ, Cantilena LR, and Independent Academic Task Force (2004) Drug-induced torsades de pointes and implications for drug development. J Cardiovasc Electrophysiol 15:475-495.

Fernandez D, Ghanta A, Kauffman GW, and Sanguinetti MC (2004) Physicochemical features of the HERG channel drug binding site. J Biol Chem 279:10120-10127. Ficker E, Kuryshev YA, Dennis AT, Obejero-Paz C, Wang L, Hawryluk P, Wible BA and Brown AM (2004) Mechanisms of arsenic-induced prolongation of cardiac repolarization. Mol Pharmacol 66:33-44.

Fitzgerald PT and Ackerman MJ (2005) Drug-induced torsades de pointes: the evolving role of pharmacogenetics. Heart Rhythm 2:S30-S37.

Frey W (1918) [About atrial fibrillation in humans, and its elimination by quinidine.] Berl Klin Wochnschr 55:417-419.

Fridericia LS (1920) [Systolic duration in the electrocardiogram in normal humans and in cardiac patients.] Acta Med Scan 53:469.

Furutani M, Trudeau MC, Hagiwara N, Seki A, Gong Q, Zhou Z, Imamura S, Nagashima H, Kasanuki H, Takao A, et al. (1999) Novel mechanism associated with an inherited cardiac arrhythmia: defective protein trafficking by the mutant HERG (G601S) potassium channel. Circulation 99:2290-2294.

Giles TD and Modlin RK (1968) Death associated with ventricular arrhythmia and thioridazine hydrochloride. JAMA 205:108-110.

Gintant GA (2008) Preclinical Torsades-de-Pointes screens: advantages and limitations of surrogate and direct approaches in evaluating proarrhythmic risk. Pharmacol Ther 119:199-209.

Guo J, Massaeli H, Li W, Xu J, Luo T, Shaw J, Kirshenbaum LA, and Zhang S (2007) Identification of $\mathrm{IKr}$ and its trafficking disruption induced by probucol in cultured neonatal rat cardiomyocytes. J Pharmacol Exp Ther 321:911-920.

Hammond TG and Pollard CE (2005) Use of in vitro methods to predict QT prolon gation. Toxicol Appl Pharmacol 207:446-450.

Hancox JC, McPate MJ, El Harchi A, and Zhang YH (2008) The hERG potassium channel and hERG screening for drug-induced torsades de pointes. Pharmacol Ther 119:118-132.

Haverkamp W, Breithardt G, Camm AJ, Janse MJ, Rosen MR, Antzelevitch C, Escande D, Franz M, Malik M, Moss A, et al. (2000) The potential for QT prolongation and pro-arrhythmia by non-anti-arrhythmic drugs: clinical and regulatory implications. Report on a Policy Conference of the European Society of Cardiology. Cardiovasc Res 47:219-233.

Hiraoka M, Sawada K, and Kawano S (1986) Effects of quinidine on plateau currents of guinea-pig ventricular myocytes. J Mol Cell Cardiol 18:1097-1106.

Hohnloser SH, van de Loo A, and Baedeker F (1995) Efficacy and proarrhythmic hazards of pharmacologic cardioversion of atrial fibrillation: prospective comparison of sotalol versus quinidine. J Am Coll Cardiol 26:852-858.

Hollister LE and Kosek JC (1965) Sudden death during treatment with phenothiazine derivatives. JAMA 192:1035-1038.

Hondeghem LM (1994) Computer aided development of antiarrhythmic agents with class IIIa properties. J Cardiovasc Electrophysiol 5:711-721.

Hondeghem LM (2006) Thorough QT/QTc not so thorough: removes torsadogenic predictors from the T-wave, incriminates safe drugs, and misses profibrillatory drugs. J Cardiovasc Electrophysiol 17:337-340.

Hondeghem LM, Carlsson L, and Duker G (2001) Instability and triangulation of the action potential predict serious proarrhythmia, but action potential duration prolongation is antiarrhythmic. Circulation 103:2004-2013.

Hondeghem LM and Hoffmann P (2003) Blinded test in isolated female rabbit heart reliably identifies action potential duration prolongation and proarrhythmic drugs: importance of triangulation, reverse use dependence, and instability. J Car diovasc Pharmacol 41:14-24.

Honig PK, Woosley RL, Zamani K, Conner DP, and Cantilena LR Jr (1992) Changes in the pharmacokinetics and electrocardiographic pharmacodynamics of terfenadine with concomitant administration of erythromycin. Clin Pharmacol Ther 52: 231-238.

Honig PK, Wortham DC, Zamani K, Conner DP, Mullin JC, and Cantilena LR (1993) Terfenadine-ketoconazole interaction. Pharmacokinetic and electrocardiographic consequences. JAMA 269:1513-1518.

Hreiche R, Morissette P, and Turgeon J (2008) Drug-induced long QT syndrome in women: review of current evidence and remaining gaps. Gend Med 5:124-135.

Imaizumi Y and Giles WR (1987) Quinidine-induced inhibition of transient outward current in cardiac muscle. Am J Physiol 253:H704-H708.

January CT and Riddle JM (1989) Early afterdepolarizations: mechanism of induction and block. A role for L-type $\mathrm{Ca}^{2+}$ current. Circ Res 64:977-990.

Jenzer HR and Hagemeijer F (1976) Quinidine syncope: torsade de pointes with low quinidine plasma concentrations. Eur J Cardiol 4:447-451.

Jervell A and Lange-Nielsen F (1957) Congenital deaf-mutism, functional heart disease with prolongation of the Q-T interval and sudden death. Am Heart $J$ 54:59-68.

Johnson EA and McKinnon MG (1957) The differential effect of quinidine and 
pyrilamine on the myocardial action potential at various rates of stimulation. $J$ Pharmacol Exp Ther 120:460-468.

Jost N, Virág L, Bitay M, Takács J, Lengyel C, Biliczki P, Nagy Z, Bogáts G, Lathrop DA, Papp JG, et al. (2005) Restricting excessive cardiac action potential and QT prolongation: a vital role for IKs in human ventricular muscle. Circulation 112: 1392-1399.

Kääb S, Ritchie MD, Crawford DC, Sinner M, Kannankeril P, Wilde A, Bezzina C, Schulze-Bahr E, Guicheney P, Bishopric N, et al. (2009) Genome-wide association study identifies novel genomic regions associated with drug-induced long QT syndrome (Abstract). Circulation 120:S580.

Kääb S, Sinner M, George A, Wilde AJ, Bezzina C, Schulze-Bahr E, Guicheney P, Bishopric N, Myerburg R, Schott JJ, et al. (2008) High-density tag SNP candidate gene analysis identifies IKs as a major modulator of genetic susceptibility to drug induced long QT syndrome (Abstract). Circulation 118:S884.

Kannankeril PJ, Roden DM, Norris KJ, Whalen SP, George AL Jr, and Murray KT (2005) Genetic susceptibility to acquired long QT syndrome: pharmacologic challenge in first-degree relatives. Heart Rhythm 2:134-140.

Kao WH, Arking DE, Post W, Rea TD, Sotoodehnia N, Prineas RJ, Bishe B, Doan BQ, Boerwinkle E, Psaty BM, et al. (2009) Genetic variations in nitric oxide synthase 1 adaptor protein are associated with sudden cardiac death in US white community-based populations. Circulation 119:940-951.

Karjalainen J, Viitasalo M, Mänttäri M, and Manninen V (1994) Relation between QT intervals and heart rates from 40 to 120 beats/min in rest electrocardiograms of men and a simple method to adjust QT interval values. $J$ Am Coll Cardio 23:1547-1553.

Kay GN, Plumb VJ, Arciniegas JG, Henthorn RW, and Waldo AL (1983) Torsade de pointes: the long-short initiating sequence and other clinical features: observations in 32 patients. J Am Coll Cardiol 2:806-817.

Kirchhof P, Franz MR, Bardai A, and Wilde AM (2009) Giant T-U waves precede torsades de pointes in long QT syndrome: a systematic electrocardiographic analysis in patients with acquired and congenital QT prolongation. J Am Coll Cardiol 54:143-149.

Krantz MJ, Lewkowiez L, Hays H, Woodroffe MA, Robertson AD, and Mehler PS (2002) Torsade de pointes associated with very-high-dose methadone. Ann Intern Med 137:501-504.

Kühlkamp V, Mewis C, Bosch R, and Seipel L (2003) Delayed sodium channel inactivation mimics long QT syndrome 3. J Cardiovasc Pharmacol 42:113-117.

Kurita T, Ohe T, Marui N, Aihara N, Takaki H, Kamakura S, Matsuhisa M, and Shimomura K (1992) Bradycardia-induced abnormal QT prolongation in patients with complete atrioventricular block with torsades de pointes. Am J Cardiol 69:628-633.

Kuryshev YA, Ficker E, Wang L, Hawryluk P, Dennis AT, Wible BA, Brown AM, Kang J, Chen XL, Sawamura K, et al. (2005) Pentamidine-induced long QT syndrome and block of hERG trafficking. J Pharmacol Exp Ther 312:316-323.

Kuryshev YA, Wang L, Wible BA, Wan X, and Ficker E (2006) Antimony-based antileishmanial compounds prolong the cardiac action potential by an increase in cardiac calcium currents. Mol Pharmacol 69:1216-1225.

Lawrence CL, Bridgland-Taylor MH, Pollard CE, Hammond TG, and Valentin JP (2006) A rabbit Langendorff heart proarrhythmia model: predictive value for clinical identification of torsades de pointes. Br J Pharmacol 149:845-860.

Lazzara R (1989) Amiodarone and torsade de pointes. Ann Intern Med 111:549-551.

Lazzara R (1993) Antiarrhythmic drugs and torsade de pointes. Eur Heart $J \mathbf{1 4}$ (Suppl. H):88-92

Lengyel C, Varró A, Tábori K, Papp JG, and Baczkó I (2007) Combined pharmacological block of $\mathrm{I}(\mathrm{Kr})$ and $\mathrm{I}(\mathrm{Ks})$ increases short-term QT interval variability and provokes torsades de pointes. Br J Pharmacol 151:941-951.

Levy RL (1922) Clinical studies of quinidine. IV. The clinical toxicology of quinidine. J Am Med Assoc 79:1108-1113.

Lherm T, Lottin F, Larbi D, Bray M, Legall C, and Caen D (2000) [Torsade de pointes after poisoning with fluoxetine alone]. Presse Med 29:306-307.

Liu DW and Antzelevitch C (1995) Characteristics of the delayed rectifier current (IKr and IKs) in canine ventricular epicardial, midmyocardial, and endocardia myocytes. A weaker IKs contributes to the longer action potential of the M cell Circ Res 76:351-365.

Liu K, Yang T, Viswanathan PC, and Roden DM (2005a) New mechanism contributing to drug-induced arrhythmia: rescue of a misprocessed LQT3 mutant. Circulation 112:3239-3246

Liu T, Choi BR, Drici MD, and Salama G (2005b) Sex modulates the arrhythmogenic substrate in prepubertal rabbit hearts with Long QT 2. J Cardiovasc Electrophysiol 16:516-524.

Liu XK, Katchman A, Drici MD, Ebert SN, Ducic I, Morad M, and Woosley RL (1998) Gender difference in the cycle length-dependent QT and potassium currents in rabbits. J Pharmacol Exp Ther 285:672-679.

Llerena A, Berecz R, de la Rubia A, Norberto MJ, and Benítez J (2000) Use of the mesoridazine/thioridazine ratio as a marker for CYP2D6 enzyme activity. Ther Drug Monit 22:397-401.

Luo S, Michler K, Johnston P, and Macfarlane PW (2004) A comparison of commonly used QT correction formulae: the effect of heart rate on the QTc of normal ECGs. $J$ Electrocardiol 37:81-90.

Makkar RR, Fromm BS, Steinman RT, Meissner MD, and Lehmann MH (1993) Female gender as a risk factor for torsades de pointes associated with cardiovascular drugs. JAMA 270:2590-2597.

Malik M, Färbom P, Batchvarov V, Hnatkova K, and Camm AJ (2002) Relation between QT and RR intervals is highly individual among healthy subjects: implications for heart rate correction of the QT interval. Heart 87:220-228.

Malik M, Hnatkova K, Ford J, and Madge D (2008) Near-thorough QT study as part of a first-in-man study. J Clin Pharmacol 48:1146-1157.

Mank-Seymour AR, Richmond JL, Wood LS, Reynolds JM, Fan YT, Warnes GR, Milos PM, and Thompson JF (2006) Association of torsades de pointes with novel and known single nucleotide polymorphisms in long QT syndrome genes. Am Heart J 152:1116-1122.
Medeiros-Domingo A, Kaku T, Tester DJ, Iturralde-Torres P, Itty A, Ye B, Valdivia C, Ueda K, Canizales-Quinteros S, Tusié-Luna MT, et al. (2007) SCN4B-encoded sodium channel beta4 subunit in congenital long-QT syndrome. Circulation 116: $134-142$

Milan DJ, Kim AM, Winterfield JR, Jones IL, Pfeufer A, Sanna S, Arking DE, Amsterdam AH, Sabeh KM, Mably JD, et al. (2009) Drug-sensitized zebrafish screen identifies multiple genes, including GINS3, as regulators of myocardial repolarization. Circulation 120:553-559.

Milberg P, Reinsch N, Osada N, Wasmer K, Mönnig G, Stypmann J, Breithardt G Haverkamp W, and Eckardt L (2005) Verapamil prevents torsade de pointes by reduction of transmural dispersion of repolarization and suppression of early afterdepolarizations in an intact heart model of LQT3. Basic Res Cardiol 100:365371.

Mitcheson JS, Chen J, Lin M, Culberson C, and Sanguinetti MC (2000) A structural basis for drug-induced long QT syndrome. Proc Natl Acad Sci USA 97:1232912333.

Mohler PJ, Le Scouarnec S, Denjoy I, Lowe JS, Guicheney P, Caron L, Driskell IM Schott JJ, Norris K, Leenhardt A, et al. (2007) Defining the cellular phenotype of "ankyrin-B syndrome" variants: human ANK2 variants associated with clinica phenotypes display a spectrum of activities in cardiomyocytes. Circulation 115: 432-441.

Mohler PJ, Schott JJ, Gramolini AO, Dilly KW, Guatimosim S, duBell WH, Song LS, Haurogné K, Kyndt F, Ali ME, et al. (2003) Ankyrin-B mutation causes type long-QT cardiac arrhythmia and sudden cardiac death. Nature 421:634-639.

Monahan BP, Ferguson CL, Killeavy ES, Lloyd BK, Troy J, and Cantilena LR Jr (1990) Torsades de pointes occurring in association with terfenadine use. JAMA 264:2788-2790.

Motté G, Coumel P, Abitbol G, Dessertenne F, and Slama R (1970) [The long QT syndrome and syncope caused by spike torsades]. Arch Mal Coeur Vaiss 63:831853.

Napolitano C, Schwartz PJ, Brown AM, Ronchetti E, Bianchi L, Pinnavaia A Acquaro G, and Priori SG (2000) Evidence for a cardiac ion channel mutation underlying drug-induced QT prolongation and life-threatening arrhythmias. $J$ Cardiovasc Electrophysiol 11:691-696.

Nattel S (2001) Effects of ionic remodeling on cardiac antiarrhythmic drug actions. $J$ Cardiovasc Pharmacol 38:809-811.

Nattel S, Duker G, and Carlsson L (2008) Model systems for the discovery and development of antiarrhythmic drugs. Prog Biophys Mol Biol 98:328-339.

Newton-Cheh C, Johnson T, Gateva V, Tobin MD, Bochud M, Coin L, Najjar SS, Zhao JH, Heath SC, Eyheramendy S, et al. (2009) Genome-wide association study identifies eight loci associated with blood pressure. Nat Genet 41:666-676.

Nishio Y, Makiyama T, Itoh H, Sakaguchi T, Ohno S, Gong YZ, Yamamoto S, Ozawa T, Ding WG, Toyoda F, et al. (2009) D85N, a KCNE1 polymorphism, is a diseasecausing gene variant in long QT syndrome. J Am Coll Cardiol 54:812-819.

Numaguchi H, Johnson JP Jr, Petersen CI, and Balser JR (2000) A sensitive mechanism for cation modulation of potassium current. Nat Neurosci 3:429-430.

Ohno S, Toyoda F, Zankov DP, Yoshida H, Makiyama T, Tsuji K, Honda T, Obayash K, Ueyama H, Shimizu W, et al. (2009) Novel KCNE3 mutation reduces repolarizing potassium current and associated with long QT syndrome. Hum Mutat 30:557-563.

Olshansky B, Martins J, and Hunt S (1982) N-acetyl procainamide causing torsades de pointes. Am J Cardiol 50:1439-1441.

Opthof T, Coronel R, Wilms-Schopman FJ, Plotnikov AN, Shlapakova IN, Danilo P Jr, Rosen MR, and Janse MJ (2007) Dispersion of repolarization in canine ventricl and the electrocardiographic $\mathrm{T}$ wave: Tp-e interval does not reflect transmura dispersion. Heart Rhythm 4:341-348.

Oros A, Beekman JD, and Vos MA (2008) The canine model with chronic, complete atrio-ventricular block. Pharmacol Ther 119:168-178.

Panaghie G and Abbott GW (2006) The impact of ancillary subunits on smallmolecule interactions with voltage-gated potassium channels. Curr Pharm Des 12:2285-2302.

Paulussen AD, Gilissen RA, Armstrong M, Doevendans PA, Verhasselt P, Smeets HJ, Schulze-Bahr E, Haverkamp W, Breithardt G, Cohen N, et al. (2004) Geneti variations of KCNQ1, KCNH2, SCN5A, KCNE1, and KCNE2 in drug-induced long QT syndrome patients. J Mol Med 82:182-188.

Pfeufer A, Sanna S, Arking DE, Müller M, Gateva V, Fuchsberger C, Ehret GB, Orrú M, Pattaro C, Köttgen A, et al. (2009) Common variants at ten loci modulate the QT interval duration in the QTSCD Study. Nat Genet 41:407-414.

Piquette RK (1999) Torsade de pointes induced by cisapride/clarithromycin interaction. Ann Pharmacother 33:22-26.

Plaster NM, Tawil R, Tristani-Firouzi M, Canún S, Bendahhou S, Tsunoda A Donaldson MR, Iannaccone ST, Brunt E, Barohn R, et al. (2001) Mutations in Kir2.1 cause the developmental and episodic electrical phenotypes of Andersen's syndrome. Cell 105:511-519.

Pollard CE, Valentin JP, and Hammond TG (2008) Strategies to reduce the risk of drug-induced QT interval prolongation: a pharmaceutical company perspective. Br J Pharmacol 154:1538-1543.

Pratt CM, Ruberg S, Morganroth J, McNutt B, Woodward J, Harris S, Ruskin J, and Moye L (1996) Dose-response relation between terfenadine (Seldane) and the QTc interval on the scalar electrocardiogram: distinguishing a drug effect from spontaneous variability. Am Heart $J$ 131:472-480.

Priori SG, Napolitano C, and Schwartz PJ (1999) Low penetrance in the long-QT syndrome: clinical impact. Circulation 99:529-533.

Rajamani S, Anderson CL, Anson BD, and January CT (2002) Pharmacological rescue of human $\mathrm{K}^{+}$channel long-QT2 mutations: human ether-a-go-go-related gene rescue without block. Circulation 105:2830-2835.

Rajamani S, Eckhardt LL, Valdivia CR, Klemens CA, Gillman BM, Anderson CL, Holzem KM, Delisle BP, Anson BD, Makielski JC, et al. (2006) Drug-induced long QT syndrome: hERG $\mathrm{K}^{+}$channel block and disruption of protein trafficking by fluoxetine and norfluoxetine. Br J Pharmacol 149:481-489.

Rautaharju PM, Zhou SH, Wong S, Calhoun HP, Berenson GS, Prineas R, and 
Davignon A (1992) Sex differences in the evolution of the electrocardiographic QT interval with age. Can J Cardiol 8:690-695.

Reant P, Lafitte S, Jaïs P, Serri K, Weerasooriya R, Hocini M, Pillois X, Clementy J, Haïssaguerre M, and Roudaut R (2005) Reverse remodeling of the left cardiac chambers after catheter ablation after 1 year in a series of patients with isolated atrial fibrillation. Circulation 112:2896-2903.

Reiffel JA and Appel G (2001) Importance of QT interval determination and renal function assessment during antiarrhythmic drug therapy. J Cardiovasc Pharmacol Ther 6:111-119.

Roden DM (1989) Magnesium treatment of ventricular arrhythmias. Am J Cardiol 63:43G-46G

Roden DM (1998) Taking the "idio" out of "idiosyncratic": predicting torsades de pointes. Pacing Clin Electrophysiol 21:1029-1034.

Roden DM (2005) An underrecognized challenge in evaluating postmarketing drug safety. Circulation 111:246-248.

Roden DM (2008) Repolarization reserve: a moving target. Circulation 118:981-982. Roden DM and Anderson ME (2000) The pause that refreshes, or does it? Mechanisms in torsades de pointes. Heart 84:235-237.

Roden DM, Bennett PB, Snyders DJ, Balser JR, and Hondeghem LM (1988) Quinidine delays IK activation in guinea pig ventricular myocytes. Circ Res 62:10551058

Roden DM and Hoffman BF (1985) Action potential prolongation and induction of abnormal automaticity by low quinidine concentrations in canine Purkinje fibers. Relationship to potassium and cycle length. Circ Res 56:857-867.

Roden DM, Iansmith DH, and Woosley RL (1987) Frequency-dependent interactions of mexiletine and quinidine on depolarization and repolarization in canine Purkinje fibers. J Pharmacol Exp Ther 243:1218-1224.

Roden DM and Viswanathan PC (2005) Genetics of acquired long QT syndrome. $J$ Clin Invest 115:2025-2032.

Roden DM, Woosley RL, and Primm RK (1986) Incidence and clinical features of the quinidine-associated long QT syndrome: implications for patient care. Am Heart $J$ 111:1088-1093.

Roden DM and Yang T (2005) Protecting the heart against arrhythmias: potassium current physiology and repolarization reserve. Circulation 112:1376-1378.

Romano C, Gemme G, and Pongiglione R (1963) [Rare cardiac arrhythmias of the pediatric age. II. Syncopal attacks due to paroxysmal ventricular fibrillation. (Presentation of 1 st case in Italian pediatric literature)]. Clin Pediatr (Bologna) 45:656-683.

Sagie A, Larson MG, Goldberg RJ, Bengtson JR, and Levy D (1992) An improved method for adjusting the QT interval for heart rate (the Framingham Heart Study). Am J Cardiol 70:797-801.

Sanguinetti MC, Jiang C, Curran ME, and Keating MT (1995) A mechanistic link between an inherited and an acquired cardiac arrhythmia: HERG encodes the IKr potassium channel. Cell 81:299-307.

Sanguinetti MC and Jurkiewicz NK (1990) Two components of cardiac delayed rectifier $\mathrm{K}^{+}$current. Differential sensitivity to block by class III antiarrhythmic agents. J Gen Physiol 96:195-215.

Schulze-Bahr E, Wang Q, Wedekind H, Haverkamp W, Chen Q, Sun Y, Rubie C, Hördt M, Towbin JA, Borggrefe M, et al. (1997) KCNE1 mutations cause Jervell and Lange-Nielsen syndrome. Nat Genet 17:267-268.

Schwartz PJ and Wolf S (1978) QT interval prolongation as predictor of sudden death in patients with myocardial infarction. Circulation 57:1074-1077.

Selzer A and Wray HW (1964) Quinidine syncope. Paroxysmal ventricular fibrillation occurring during treatment of chronic atrial arrhythmias. Circulation 30: 17-26.

Sesti F, Abbott GW, Wei J, Murray KT, Saksena S, Schwartz PJ, Priori SG, Roden DM, George AL Jr, and Goldstein SA (2000) A common polymorphism associated with antibiotic-induced cardiac arrhythmia. Proc Natl Acad Sci USA 97:1061310618.

Sethuraman V and Sun Q (2009) Impact of baseline ECG collection on the planning, analysis and interpretation of 'thorough' QT trials. Pharm Stat 8:113-124.

Shah RR(2005a) Drug-induced QT interval prolongation-regulatory guidance and perspectives on hERG channel studies. Novartis Found Symp 266:251-280; discussion $280-255$

Shah RR (2005b) Drugs, QTc interval prolongation and final ICH E14 guideline: an important milestone with challenges ahead. Drug Saf 28:1009-1028.

Shah RR and Hondeghem LM (2005) Refining detection of drug-induced proarrhythmia: QT interval and TRIaD. Heart Rhythm 2:758-772.

Sherazi S, DiSalle M, Daubert JP, and Shah AH (2008) Moxifloxacin-induced torsades de pointes. Cardiol $J$ 15:71-73.

Shimizu W, McMahon B, and Antzelevitch C (1999) Sodium pentobarbital reduces transmural dispersion of repolarization and prevents torsades de Pointes in models of acquired and congenital long QT syndrome. J Cardiovasc Electrophysiol 10:154-164.

Shimizu W, Ohe T, Kurita T, Kawade M, Arakaki Y, Aihara N, Kamakura S, Kamiya $\mathrm{T}$, and Shimomura K (1995) Effects of verapamil and propranolol on early afterdepolarizations and ventricular arrhythmias induced by epinephrine in congenital long QT syndrome. J Am Coll Cardiol 26:1299-1309.

Silva J and Rudy Y (2005) Subunit interaction determines IKs participation in cardiac repolarization and repolarization reserve. Circulation 112:1384-1391.

Sipido KR, Volders PG, de Groot SH, Verdonck F, Van de Werf F, Wellens HJ, and Vos MA (2000) Enhanced $\mathrm{Ca}^{2+}$ release and $\mathrm{Na} / \mathrm{Ca}$ exchange activity in hypertrophied canine ventricular myocytes: potential link between contractile adaptation and arrhythmogenesis. Circulation 102:2137-2144.

Snook J, Boothman-Burrell D, Watkins J, and Colin-Jones D (1988) Torsade de pointes ventricular tachycardia associated with astemizole overdose. $\mathrm{Br} \mathrm{J} \mathrm{Clin}$ Pract 42:257-259.

Snyders DJ and Chaudhary A (1996) High affinity open channel block by dofetilide of HERG expressed in a human cell line. Mol Pharmacol 49:949-955.

Soyka LF, Wirtz C, and Spangenberg RB (1990) Clinical safety profile of sotalol in patients with arrhythmias. Am J Cardiol 65:74A-81A.
Splawski I, Timothy KW, Sharpe LM, Decher N, Kumar P, Bloise R, Napolitano C, Schwartz PJ, Joseph RM, Condouris K, et al. (2004) Ca(V)1.2 calcium channel dysfunction causes a multisystem disorder including arrhythmia and autism. Cell 119:19-31.

Splawski I, Tristani-Firouzi M, Lehmann MH, Sanguinetti MC, and Keating MT (1997) Mutations in the hminK gene cause long QT syndrome and suppress IKs function. Nat Genet 17:338-340.

Stadnicka A, Bosnjak ZJ, Kampine JP, and Kwok WM (2000) Modulation of cardiac inward rectifier $\mathrm{K}^{+}$current by halothane and isoflurane. Anesth Analg 90:824833

Stambler BS, Wood MA, Ellenbogen KA, Perry KT, Wakefield LK, and VanderLugt JT (1996) Efficacy and safety of repeated intravenous doses of ibutilide for rapid conversion of atrial flutter or fibrillation. Ibutilide Repeat Dose Study Investigators. Circulation 94:1613-1621.

Strasberg B, Kusniec J, Erdman S, Lewin RF, Arditti A, Sclarovsky S, and Agmon J (1986) Polymorphous ventricular tachycardia and atrioventricular block. Pacing Clin Electrophysiol 9:522-526.

Strauss HC, Bigger JT Jr, and Hoffman BF (1970) Electrophysiologial and betareceptor blocking effects of MJ 1999 on dog and rabbit cardiac tissue. Circ Res 26:661-678.

Sun ZQ, Thomas GP, and Antzelevitch C (2001) Chromanol 293B inhibits slowly activating delayed rectifier and transient outward currents in canine left ventricular myocytes. J Cardiovasc Electrophysiol 12:472-478.

Thomas D, Gut B, Wendt-Nordahl G, and Kiehn J (2002) The antidepressant drug fluoxetine is an inhibitor of human ether-a-go-go-related gene (HERG) potassium channels. J Pharmacol Exp Ther 300:543-548.

Thompson D and Oster G (1996) Use of terfenadine and contraindicated drugs. JAMA 275:1339-1341.

Thompson KA, Blair IA, Woosley RL, and Roden DM (1987) Comparative in vitro electrophysiology of quinidine, its major metabolites and dihydroquinidine. $J$ Pharmacol Exp Ther 241:84-90.

Thompson KA, Murray JJ, Blair IA, Woosley RL, and Roden DM (1988) Plasma concentrations of quinidine, its major metabolites, and dihydroquinidine in patients with torsades de pointes. Clin Pharmacol Ther 43:636-642.

Thomsen MB, Beekman JD, Attevelt NJ, Takahara A, Sugiyama A, Chiba K, and Vos MA (2006) No proarrhythmic properties of the antibiotics Moxifloxacin or Azithromycin in anaesthetized dogs with chronic-AV block. $\mathrm{Br} J$ Pharmacol 149: 1039-1048.

Thomsen MB, Oros A, Schoenmakers M, van Opstal JM, Maas JN, Beekman JD, and Vos MA (2007) Proarrhythmic electrical remodelling is associated with increased beat-to-beat variability of repolarisation. Cardiovasc Res 73:521-530.

Topilski I, Rogowski O, Rosso R, Justo D, Copperman Y, Glikson M, Belhassen B Hochenberg M, and Viskin S (2007) The morphology of the QT interval predicts torsade de pointes during acquired bradyarrhythmias. J Am Coll Cardiol 49:320 328

Torp-Pedersen C, Møller M, Bloch-Thomsen PE, Køber L, Sandøe E, Egstrup K, Agner E, Carlsen J, Videbaek J, Marchant B, et al. (1999) Dofetilide in patient with congestive heart failure and left ventricular dysfunction. Danish Investigations of Arrhythmia and Mortality on Dofetilide Study Group. $N$ Engl J Med 341:857-865.

Tsai WC, Tsai LM, and Chen JH (1997) Combined use of astemizole and ketocon azole resulting in torsade de pointes. $J$ Formos Med Assoc 96:144-146.

Tzivoni D, Banai S, Schuger C, Benhorin J, Keren A, Gottlieb S, and Stern S (1988) Treatment of torsade de pointes with magnesium sulfate. Circulation 77:392-397. Ueda K, Valdivia C, Medeiros-Domingo A, Tester DJ, Vatta M, Farrugia G, Ackerman MJ, and Makielski JC (2008) Syntrophin mutation associated with long QT syndrome through activation of the nNOS-SCN5A macromolecular complex. Proc Natl Acad Sci USA 105:9355-9360.

van Opstal JM, Verduyn SC, Leunissen HD, de Groot SH, Wellens HJ, and Vos MA (2001) Electrophysiological parameters indicative of sudden cardiac death in the dog with chronic complete AV-block. Cardiovasc Res 50:354-361.

Vatta M, Ackerman MJ, Ye B, Makielski JC, Ughanze EE, Taylor EW, Tester DJ, Balijepalli RC, Foell JD, Li Z, et al. (2006) Mutant caveolin-3 induces persistent late sodium current and is associated with long-QT syndrome. Circulation 114: $2104-2112$.

Vincze D, Farkas AS, Rudas L, Makra P, Csík N, Leprán I, Forster T, Csanády M, Papp JG, Varró A, et al. (2008) Relevance of anaesthesia for dofetilide-induced torsades de pointes in alpha1-adrenoceptor-stimulated rabbits. Br J Pharmacol 153:75-89

Viskin S, Zelster D, and Antzelevitch C (2004) When u say "U Waves," what do u mean? Pacing Clin Electrophysiol 27:145-147.

Vorperian VR, Zhou Z, Mohammad S, Hoon TJ, Studenik C, and January CT (1996) Torsade de pointes with an antihistamine metabolite: potassium channel blockade with desmethylastemizole. $J$ Am Coll Cardiol 28:1556-1561.

Vos MA, de Groot SH, Verduyn SC, van der Zande J, Leunissen HD, Cleutjens JP, van Bilsen M, Daemen MJ, Schreuder JJ, Allessie MA, et al. (1998) Enhanced susceptibility for acquired torsade de pointes arrhythmias in the dog with chronic, complete AV block is related to cardiac hypertrophy and electrical remodeling. Circulation 98:1125-1135.

Vos MA, Gorenek B, Verduyn SC, van der Hulst FF, Leunissen JD, Dohmen L, and Wellens HJ (2000) Observations on the onset of torsade de pointes arrhythmias in the acquired long QT syndrome. Cardiovasc Res 48:421-429.

Vos MA, Verduyn SC, Gorgels AP, Lipcsei GC, and Wellens HJ (1995) Reproducible induction of early afterdepolarizations and torsade de pointes arrhythmias by $\mathrm{d}$-sotalol and pacing in dogs with chronic atrioventricular block. Circulation 91: 864-872.

Voss F, Opthof T, Marker J, Bauer A, Katus HA, and Becker R (2009) There is no transmural heterogeneity in an index of action potential duration in the canine left ventricle. Heart Rhythm 6:1028-1034.

Walker AM, Szneke P, Weatherby LB, Dicker LW, Lanza LL, Loughlin JE, Yee CL, 
and Dreyer NA (1999) The risk of serious cardiac arrhythmias among cisapride users in the United Kingdom and Canada. Am J Med 107:356-362.

Wang D, Patel C, Cui C, and Yan GX (2008) Preclinical assessment of drug-induced proarrhythmias: role of the arterially perfused rabbit left ventricular wedge preparation. Pharmacol Ther 119:141-151.

Wang Q, Curran ME, Splawski I, Burn TC, Millholland JM, VanRaay TJ, Shen J, Timothy KW, Vincent GM, de Jager T, et al. (1996) Positional cloning of a novel potassium channel gene: KVLQT1 mutations cause cardiac arrhythmias. Nat Genet 12:17-23.

Wang Q, Shen J, Li Z, Timothy K, Vincent GM, Priori SG, Schwartz PJ, and Keating MT (1995a) Cardiac sodium channel mutations in patients with long QT syndrome, an inherited cardiac arrhythmia. Hum Mol Genet 4:1603-1607.

Wang Q, Shen J, Splawski I, Atkinson D, Li Z, Robinson JL, Moss AJ, Towbin JA, and Keating MT (1995b) SCN5A mutations associated with an inherited cardiac arrhythmia, long QT syndrome. Cell 80:805-811.

Wang S, Morales MJ, Liu S, Strauss HC, and Rasmusson RL (1997) Modulation of HERG affinity for E-4031 by $\left[\mathrm{K}^{+}\right]$o and C-type inactivation. FEBS Lett 417:43-47.

Ward OC (1964) A new familial cardiac syndrome in children. J Ir Med Assoc 54:103-106.

Wattigney WA, Mensah GA, and Croft JB (2002) Increased atrial fibrillation mortality: United States, 1980-1998. Am J Epidemiol 155:819-826.

Weissenburger J, Nesterenko VV, and Antzelevitch C (2000) Transmural heterogeneity of ventricular repolarization under baseline and long QT conditions in the canine heart in vivo: torsades de pointes develops with halothane but not pentobarbital anesthesia. J Cardiovasc Electrophysiol 11:290-304.

Wenckebach KF (1923) Cinchona derivatives in the treatment of heart disorders. JAMA 81:472-474.

Wilke RA, Lin DW, Roden DM, Watkins PB, Flockhart D, Zineh I, Giacomini KM, and Krauss RM (2007) Identifying genetic risk factors for serious adverse drug reactions: current progress and challenges. Nat Rev Drug Discov 6:904-916.

Woosley RL (2000) Drug labeling revisions-guaranteed to fail? JAMA 284:30473049 .

Woosley RL, Chen Y, Freiman JP, and Gillis RA (1993) Mechanism of the cardiotoxic actions of terfenadine. JAMA 269:1532-1536.

Wu L, Shryock JC, Song Y, and Belardinelli L (2006) An increase in late sodium current potentiates the proarrhythmic activities of low-risk QT-prolonging drugs in female rabbit hearts. $J$ Pharmacol Exp Ther 316:718-726.

Wu Y, Roden DM, and Anderson ME (1999) Calmodulin kinase inhibition prevents development of the arrhythmogenic transient inward current. Circ Res 84:906912.

Wyse DG, Waldo AL, DiMarco JP, Domanski MJ, Rosenberg Y, Schron EB, Kellen JC, Greene HL, Mickel MC, Dalquist JE, et al. (2002) A comparison of rate control and rhythm control in patients with atrial fibrillation. $N$ Engl $J$ Med 347:18251833

Xiao L, Xiao J, Luo X, Lin H, Wang Z, and Nattel S (2008) Feedback remodeling of cardiac potassium current expression: a novel potential mechanism for control of repolarization reserve. Circulation 118:983-992.

Yan GX and Antzelevitch C (1996) Cellular basis for the electrocardiographic J wave. Circulation 93:372-379.

Yan GX, Rials SJ, Wu Y, Liu T, Xu X, Marinchak RA, and Kowey PR (2001) Ventricular hypertrophy amplifies transmural repolarization dispersion and induces early afterdepolarization. Am J Physiol Heart Circ Physiol 281:H1968H1975.

Yan GX, Shimizu W, and Antzelevitch C (1998) Characteristics and distribution of M cells in arterially perfused canine left ventricular wedge preparations. Circulation 98:1921-1927.

Yang P, Kanki H, Drolet B, Yang T, Wei J, Viswanathan PC, Hohnloser SH, Shimizu W, Schwartz PJ, Stanton M, et al. (2002) Allelic variants in long-QT disease genes in patients with drug-associated torsades de pointes. Circulation 105:1943-1948.

Yang T and Roden DM (1996) Extracellular potassium modulation of drug block of IKr. Implications for torsade de pointes and reverse use-dependence. Circulation 93:407-411.

Yang T, Snyders D, and Roden DM (2001) Drug block of I(kr): model systems and relevance to human arrhythmias. J Cardiovasc Pharmacol 38:737-744.

Yang T, Snyders DJ, and Roden DM (1997) Rapid inactivation determines the rectification and $\left[\mathrm{K}^{+}\right]$o dependence of the rapid component of the delayed rectifier $\mathrm{K}^{+}$current in cardiac cells. Circ Res 80:782-789.

Yang Y, Yang Y, Liang B, Liu J, Li J, Grunnet M, Olesen SP, Rasmussen HB, Ellinor PT, Gao L, et al. (2010) Identification of a Kir3.4 mutation in congenital long QT syndrome. Am J Hum Genet 86:872-880.

Zareba W, Moss AJ, Locati EH, Lehmann MH, Peterson DR, Hall WJ, Schwartz PJ, Vincent GM, Priori SG, Benhorin J, et al. (2003) Modulating effects of age and gender on the clinical course of long QT syndrome by genotype. J Am Coll Cardiol 42:103-109.

Zhang S, Zhou Z, Gong Q, Makielski JC, and January CT (1999) Mechanism of block and identification of the verapamil binding domain to HERG potassium channels. Circ Res 84:989-998.

Zhou Z, Vorperian VR, Gong Q, Zhang S, and January CT (1999) Block of HERG potassium channels by the antihistamine astemizole and its metabolites desmethylastemizole and norastemizole. J Cardiovasc Electrophysiol 10:836-843.

Zygmunt AC, Eddlestone GT, Thomas GP, Nesterenko VV, and Antzelevitch C (2001) Larger late sodium conductance in M cells contributes to electrical heter ogeneity in canine ventricle. Am J Physiol Heart Circ Physiol 281:H689-H697. 